\title{
Phospholipid Component Defines Pharmacokinetic and Pharmacodynamic Properties of Synthetic High-Density Lipoproteins ${ }^{[\mathrm{S}}$
}

\author{
Maria V. Fawaz, ${ }^{1}$ @Sang Yeop Kim, ${ }^{1}$ Dan Li, Ran Ming, Ziyun Xia, Karl Olsen, \\ Irina D. Pogozheva, (John J.G. Tesmer, and (ㄱ)Anna Schwendeman
} Departments of Medicinal Chemistry (M.V.F., I.D.P.) and Pharmaceutical Sciences (S.Y.K., D.L., R.M., Z.X., K.O., A.S.), College of
Pharmacy, and Biointerfaces Institute (A.S.), University of Michigan, Ann Arbor, Michigan; and Department of Biological

Sciences, Purdue University, West Lafayette, Indiana (J.J.G.T.)

Received February 26, 2019; accepted November 18, 2019

\begin{abstract}
Synthetic high-density lipoprotein (sHDL) nanoparticles composed of apolipoprotein A-I mimetic peptide and phospholipids have been shown to reduce atherosclerosis in animal models. Cholesterol is mobilized from atheroma macrophages by sHDL into the blood compartment and delivered to the liver for elimination. Historically, sHDL drug discovery efforts were focused on optimizing peptide sequences for interaction with cholesterol cellular transporters rather than understanding how both sHDL components, peptide and lipid, influence its pharmacokinetic and pharmacodynamic profiles. We designed two sets of SHDL having either identical phospholipid but variable peptide sequences with different plasma stability or identical peptide and phospholipids with variable fatty acid chain length and saturation. We found that sHDL prepared with proteolytically stable 22A-P peptide had 2 -fold longer circulation half-time relative to the less stable
\end{abstract}

22A peptide. Yet, longer half-life did not translate into any improvement in cholesterol mobilization. In contrast, sHDL with variable phospholipid compositions showed significant differences in phospholipid PK, with distearoyl phosphatidylcholinebased SHDL demonstrating the longest half-life of 6.0 hours relative to 1.0 hour for palmitoyl-oleoyl phosphatidylcholinebased SHDL. This increase in half-life corresponded to an approx. 6.5-fold increase in the area under the curve for the mobilized cholesterol. Therefore, the phospholipid component in SHDL plays a major role in cholesterol mobilization in vivo and should not be overlooked in the design of future $\mathrm{SHDL}$.

\section{SIGNIFICANCE STATEMENT}

The phospholipid composition in SHDL plays a critical role in determining half-life and cholesterol mobilization in vivo.

\section{Introduction}

Reverse cholesterol transport (RCT) is a mechanism of cholesterol removal from the periphery to the liver for elimination. This transport starts when lipid-poor apolipoprotein A-I (ApoA-I) facilitates extracellular efflux of phospholipids and cholesterol through the transmembrane ATP-binding cassette transporter A1 (ABCA1) resulting in formation of pre- $\beta$ highdensity lipoprotein (HDL) particles. Pre- $\beta$ HDLs then interact

This project was supported by American Heart Association 13SDG17230049 (A.S.); National Institutes of Health [R01GM113832 (A.S.), R01HL122416 (J.J.G.T. and A.S.), R01HL122416 (A.S.), T32GM07767 (M.V.F.), T32HL125242 (M.V.F.)]; MedImmune (A.S. and J.J.G.T.); Upjohn award (A.S.); Barbour fellowship (D.L.); and American Foundation for Pharmaceutical Education fellowship (M.V.F.).

${ }^{1}$ M.V.F. and S.Y.K. contributed equally to this work

https://doi.org/10.1124/jpet.119.257568.

S This article has supplemental material available at jpet.aspetjournals.org. with lecithin/cholesterol acyltransferase (LCAT), an enzyme responsible for cholesterol esterification, leading to formation of larger mature HDLs. Mature HDLs can either deliver esterified cholesterol (EC) cargo directly to the liver for elimination through scavenger receptor class B type I (SR-BI) or transfer EC to LDL by interaction with cholesterol ester transfer protein (CETP) for the elimination by the liver following LDL receptor-mediated uptake.

The idea of using reconstituted (rHDL) or synthetic (sHDL) HDL for the treatment of cardiovascular disease has been prominent in the past 20 years, with several therapies reaching clinical trials ((Nissen et al., 2003; Tardif et al., 2007; Tricoci et al., 2015; NCT03473223)). Although some clinical trials for rHDL products were successful ((Nissen et al., 2003; Tardif et al., 2007; NCT03473223)), others failed (Andrews et al., 2017; Nicholls et al., 2018). A 17,400-patient phase 3 trial (AEGIS-II) is currently ongoing for CSL-112 to show

ABBREVIATIONS: ABCA1, ATP-binding cassette transporter A1; ApoA-I, apolipoprotein A-I; AUEC, area under the total effect curve; CD, circular dichroism; DHE, dehydroergosterol; DLS, dynamic light scattering; DMPC, 1,2-dimyristoyl-sn-glycero-3-phosphocholine; DPPC, 1,2-dipalmitoylsn-glycero-3-phosphocholine; DSPC, 1,2-distearoyl-sn-glycero-3-phosphocholine; EC, esterified cholesterol; FC, free cholesterol; HDL, highdensity lipoprotein; LCAT, lecithin/cholesterol acyltransferase; LC-MS, liquid chromatography-mass spectrometry; PD, pharmacodynamic(s); PK, pharmacokinetic(s); PL, phospholipid; POPC, 1-palmitoyl-2-oleoyl-sn-glycero-3-phosphocholine; PBS, phosphate-buffered saline; RCT, reverse cholesterol transport; sHDL, synthetic high-density lipoprotein; Tm, transition temperatures. 
possible reduction of major adverse cardiovascular events in subjects with acute coronary syndrome (NCT03473223). The two most advanced sHDL products, CSL-112 and CER-001, both contain ApoA-I but differ in their lipid composition. CSL-112 is prepared from unsaturated soybean phosphatidylcholine, and CER-001 is composed of primarily saturated sphingomyelin (Andrews et al., 2017). Recently, we have shown that the type of phospholipid used in sHDL preparation is critical for its anti-inflammatory and anti-atherosclerotic properties (Schwendeman et al., 2015). Several other studies had examined the effects of phospholipid composition on the ability of sHDL to efflux cholesterol and interact with LCAT in vitro (Davidson et al., 1995; Bolin and Jonas, 1996; Sparks et al., 1998), yet the impact of phospholipid chain length and saturation on sHDL pharmacodynamics (PD) in vivo has not been systematically examined.

In contrast, a significant body of research has been performed to develop short peptides [2F (18A), D-4F, L-4F, 5A, 22A, and ATI-5261] as cost-efficient, safe, and easily scalable alternatives to a full-length ApoA-I (Dasseux et al., 1999; Remaley et al., 2001; Miles et al., 2004; Navab et al., 2005a,b; Sethi et al., 2008; Wool et al., 2008; Vecoli et al., 2011). These ApoA-I mimetic peptides have been optimized with the goals of improving several properties, such as ABCA1-mediated cholesterol efflux and the ability to activate LCAT and facilitate cholesterol esterification; enhancing antioxidant properties; improving chemical stability; and reducing hemolytic side-effects (Dasseux et al., 1999; Amar et al., 2010; Bielicki et al., 2010; Li et al., 2015). Most ApoA-I mimetics were optimized as "naked" or lipid-free peptides in vitro and in vivo and only a few studies examined the pharmacological activity of peptide-based sHDL (Amar et al., 2010; Tang et al., 2017).

Thus, we decided to systematically evaluate the effect of both peptide sequence and phospholipid composition of SHDL on a nanoparticle's ability to mobilize and esterify cholesterol in vitro and in vivo. For our studies, we used the first ApoA-I mimetic peptide (22A) that reached clinical trials as part of the sHDL product called ETC-642 (Khan et al., 2003; Miles et al., 2004). ETC-642 contained 22A ApoA-I mimetic peptide, which was optimized for its ability to bind phospholipids and activate LCAT (Dasseux et al., 1999; Di Bartolo et al., 2011). Although ETC-642 successfully completed single- and multiple-dose trials in dyslipidemia patients, it was recently discovered by us that $22 \mathrm{~A}$ peptide undergoes rapid hydrolysis in plasma to form the $21 \mathrm{~A}$ peptide, which lacks the C-terminal lysine, a residue potentially important for LCAT activation (Navab et al., 2006; Tang et al., 2017). We hypothesized that the addition of a proline moiety after the labile lysine (22A-P) would be able to protect $22 \mathrm{~A}$ from proteolysis and result in longer circulation time while retaining LCAT activity in vivo. Thus, we prepared a set of sHDL particles using 22A, 21A, and 22A-P peptides while keeping lipid composition constant.

A second set of sHDL was prepared by varying only the phospholipid component and keeping the peptide component, 22A, constant. We used phospholipids of different chain length and saturation, including 1-palmitoyl-2-oleoyl-sn-glycero-3-phosphocholine (POPC), 1,2-dimyristoyl-sn-glycero-3-phosphocholine (DMPC), 1,2-dipalmitoyl-sn-glycero-3-phosphocholine (DPPC) or 1,2distearoyl-sn-glycero-3-phosphocholine (DSPC) known for their differences in cholesterol binding affinity and LCAT interaction (Assmann et al., 1978; Subbaiah et al., 1992; Ramstedt and
Slotte, 1999). Phospholipids with longer, saturated fatty acid chains, such as DPPC and DSPC, have higher affinity for cholesterol binding and higher physical stability owing to their high transition temperatures $\left(\mathrm{T}_{\mathrm{m}}\right)$ of 41 and $55^{\circ} \mathrm{C}$, respectively (Small, 1986; Ramstedt and Slotte, 1999; OhvoRekilä et al., 2002). In contrast, unsaturated phospholipids like POPC $\left(\mathrm{T}_{\mathrm{m}}=-2^{\circ} \mathrm{C}\right)$ and those with shorter fatty acid chains like DMPC $\left(\mathrm{T}_{\mathrm{m}}=23^{\circ} \mathrm{C}\right)$ form fluid bilayers at physiologic temperature facilitating LCAT-sHDL binding. The unsaturated fatty acids are superior substrates for LCAT esterification activity (Assmann et al., 1978; Parks and Gebre, 1997). By comparing two sets of sHDL with varying peptide and lipid components side by side, we expected to be able to elucidate the relative contribution of both components to cholesterol efflux and engagement of LCAT in vitro as well as the overall pharmacokinetic $(\mathrm{PK})$ and pharmacodynamic behavior of sHDL in vivo.

\section{Materials and Methods}

Materials. 22A (PVLDLFRELLNELLEALKQKLK), 21A (PVLDLFRELLNELLEALKQKL), and 22A-P (PVLDLFRELLNELLEALKQKLKP) were synthesized by Genscript (Piscataway, NJ), using solid-phase Fmoc (9-fluorenylmethyl carbamate) protection chemistry, and purified with reverse phase chromatography ( $>95 \%$ pure). The 5A peptide(DWLKAFYDKVAEKLKEAF-P-DWAKAAYDKAAEKAKEAA) was obtained from Bachem Americas Inc (Torrance, CA). Phospholipids including 1,2-dimyristoyl-sn-glycero-3-phosphocholine, 1,2-dipalmitoyl$s n$-glycero-3-phosphocholine, 1,2-distearoyl-sn-glycero-3-phosphocholine, and 1-palmitoyl-2-oleoyl-sn-glycero-3-phosphocholine were purchased from NOF America Corporation. Ergosta-5,7,9(11), 22-tetraen-3 $\beta$-ol (dehydroergosterol, DHE), cholesterol oxidase was obtained from SigmaAldrich (St. Louis, MO). Cholesterol $\left(1,2-{ }^{3} \mathrm{H}(\mathrm{N})\right]$ was purchased from Perkin Elmer. Anti-human ApoA-I horseradish peroxidase-conjugated (HRP) antibody (1:1000 dilution) was purchased from Meridian Life Science (Memphis, TN). Recombinant human lecithin cholesterol acyl transferase was kindly provided by MedImmune (Gaithersburg, MD). All other materials were obtained from commercial sources.

Preparation and Characterization of Synthetic High-Density Lipoproteins. sHDL composed of a peptide (22A, 21A, or 22A-P) and phospholipid (DMPC, POPC, DPPC, or DSPC) were prepared by a colyophilization procedure (Schwendeman et al., 2015). Briefly, peptide and phospholipids were dissolved in glacial acetic acid, mixed at 1:2 w/w ratio of peptide/lipid, and lyophilized overnight. The powder was hydrated with phosphate-buffered saline (PBS; $\mathrm{pH}$ 7.4) to make $10 \mathrm{mg} / \mathrm{ml} \mathrm{sHDL}$ and cycled between $55^{\circ} \mathrm{C}$ (10 minutes) and room temperature (10 minutes) to facilitate sHDL formation. The resulting sHDL complexes were analyzed by gel permeation chromatography (GPC) for purity at $1 \mathrm{mg} / \mathrm{ml}$ using a $7.8 \mathrm{~mm} \times 30 \mathrm{~cm}$ Tosoh TSK gel G3000SWxl column (Tosoh Bioscience, King of Prussia, PA) with UV detection at $220 \mathrm{~nm}$. The HDL hydrodynamic diameters were determined by dynamic light scattering (DLS) using a Zetasizer Nano ZSP, Malvern Instruments (Westborough, MA). The volume intensity average values were reported. The $\alpha$-helical content of free and lipid-bound peptide was determined by Jasco J715 (Jasco, Easton, MD) circular dichroism (CD) spectropolarimeter. Samples at $0.1 \mathrm{mg} / \mathrm{ml}$ concentration in $10 \mathrm{mM}$ phosphate buffer $(\mathrm{pH}$ 7.4) or buffer alone were loaded into a quartz cuvette $(\mathrm{d}=0.2-\mathrm{cm}$ path length), and CD spectra from 190 to $260 \mathrm{~nm}$ were recorded at $37^{\circ} \mathrm{C}$. Buffer spectra were subtracted from each peptide or sHDL sample. Data analysis was conducted using CDPro analysis software and the percent helical content for each sample was calculated via CONTIN analysis method with the reference soluble-membrane protein 56 database (Sreerama and Woody, 2000).

Generation of Helical Wheel Peptide Models and Calculation of Lipid Binding Parameters. Helical wheel plots of 22A, $21 \mathrm{~A}$, and 22A-P peptides were created by Helixator (http://tcdb.org/ progs/helical_wheel.php). This program displayed a peptide sequence 
looking down the axis of the alpha helix with aliphatic residues shown as blue circles. The hydrophobic momentum of $22 \mathrm{~A}, 21 \mathrm{~A}$, and $22 \mathrm{~A}-\mathrm{P}$ peptides was calculated using the three-dimensional Hydrophobic Moment Vector Calculator (http://www.ibg.kit.edu/HM/) (Reißer et al., 2014). The helix stability $\left(\Delta \mathrm{G}_{\mathrm{hel}}\right)$, transfer energy from water to membrane ( $\left.\Delta \mathrm{G}_{\text {trans }}\right)$, and parameters of spatial positions in membranes (tilt angle and membrane penetration depth) for each ApoA-I-mimetic peptide were calculated by the Folding of Membrane-Associated Peptide server (Lomize et al., 2017) and the Positioning of Proteins in Membranes (PPM) server (Lomize et al., 2012).

Cholesterol Efflux Assay In Vitro. Cholesterol efflux studies were performed as described by Remaley et al. (2003). Briefly, RAW 264.7, BHK-Mock, and BHK stably transfected with human ABCA1 cDNA cell lines were labeled for 24 hours with $1 \mu \mathrm{Ci} / \mathrm{ml}$ of $\left[{ }^{3} \mathrm{H}\right]$ cholesterol in minimum Dulbecco's modified Eagle's medium (DMEM) containing $0.2 \mathrm{mg} / \mathrm{ml}$ of fatty acid-free bovine serum albumin (BSA). The BHK-MOCK and BHK-ABCA1 cell lines were then treated with $10 \mathrm{nM}$ mifepristone for 18 hours to selectively induce the expression of ABCA1 cholesterol transporter for BHK-ABCA1. ABCA1 transporter was not selectively induced in the RAW 264.7 cell line. Following the radiolabeling or induction step, peptides (22A, 21A, or 22A-P) or sHDL (21A-DMPC, 22A-P-DMPC, 22A-DMPC, 22A-POPC, 22A-DPPC, or 22A-DSPC) were added at $0.01,0.03$, and $0.1 \mathrm{mg} / \mathrm{ml}$ concentration using DMEM-BSA media. After 18 hours of incubation with cholesterol acceptors, media were collected and cells were lysed in $0.5 \mathrm{ml}$ of $0.1 \%$ SDS and $0.1 \mathrm{~N} \mathrm{NaOH}$ for 2 hours. Radioactive counts in media and cell fractions were measured by liquid scintillation counting (TriCarb 2910 TR; PerkinElmer), and percent cholesterol efflux was calculated by dividing media counts by the sum of media and cell counts.

Phospholipid Lipolysis by LCAT. The rate of phospholipid (POPC, DMPC, DPPC, or DSPC) lipolysis was evaluated by incubating $15 \mu \mathrm{g} / \mathrm{ml}$ of rhLCAT with $0.1 \mathrm{mg} / \mathrm{ml}$ of sHDL (on the basis of total lipid concentration) in $0.1 \mathrm{M}$ sodium phosphate buffer $\mathrm{pH} 7.4$ for $0,5,15,30$, 60,90 , and 120 minutes. The LCAT-sHDL reaction aliquots were collected into methanol $(1: 5 \mathrm{v} / \mathrm{v})$ and vortexed to stop the lipolysis reaction at each time point. The amount of POPC, DMPC, DPPC, or DSPC remaining at each time point was measured by Waters UPLCMS equipped with QDa Mass Detector (Milford, MA). Chromatographic separation was achieved on Acquity BEH300 $1.7 \mu \mathrm{m}$ HILIC $2.1 \times 50 \mathrm{~mm}$ column with gradient elution at $0.65 \mathrm{ml} / \mathrm{min}$ : mobile phase $\mathrm{A}\left(\mathrm{H}_{2} \mathrm{O} / 0.1 \%\right.$ formic acid), mobile phase $\mathrm{B}$ (acetonitrile/ $0.1 \%$ formic acid), and mobile phase $\mathrm{C}$ (100 $\mathrm{mM}$ ammonium formate) as follows: $0-0.7$ minutes (5\%-17\% A, $90 \%-78 \% \mathrm{~B}$, and $5 \%-5 \% \mathrm{C}$ ), $0.7-0.71$ minutes $(17 \%-5 \% \mathrm{~A}, 78 \%-90 \% \mathrm{~B}$, and $5 \%-5 \% \mathrm{C})$, and 0.71-3 minutes (17\%-5\% A, 78\%-90\% B, and 5\%-5\% C). Mass spectra were acquired in the positive ion mode with the mass range set at $\mathrm{m} / z$ $150-1250$ and POPC was detected at $760.7 \mathrm{amu}, \mathrm{DMPC}$ at $678.7 \mathrm{amu}$, DPPC at $734.7 \mathrm{amu}$, and DSPC at $790.7 \mathrm{amu}$. Data analysis was performed with Waters Empower software. A plot of POPC, DMPC, DPPC, or DSPC area under the curve over time was generated for each sHDL sample. The rate of LCAT lipolysis was calculated from the linear slope of the $\log 10$ (concentration) versus time.

Cholesterol Esterification by LCAT Assay. Two different sets of sHDL containing dehydroergosterol were prepared via the thin-film method. Briefly, the first set was made from POPC, DPPC, and DHE combined at a 4.5:4.5:1 molar ratio in chloroform and then mixed with peptide $(22 \mathrm{~A}, 21 \mathrm{~A}$, or $22 \mathrm{~A}-\mathrm{P})$ at $2: 1 \mathrm{lipid} /$ peptide weight ratio in methanol/water $(4: 3 \mathrm{v} / \mathrm{v})$. The second set was prepared from POPC, DMPC, DPPC, or DSPC and DHE at a 9:1 molar ratio, then mixed with $22 \mathrm{~A}$ peptide at $2: 1 \mathrm{lipid} /$ peptide weight ratio in methanol/water $(4: 3$ $\mathrm{v} / \mathrm{v})$. The solvent was removed under nitrogen flow at room temperature and then in a vacuum oven overnight. The lipid film was hydrated with $20 \mathrm{mM}$ phosphate buffer containing $1 \mathrm{mM}$ EDTA ( $\mathrm{pH}$ 7.4) followed by a 5 -minute water bath sonication at room temperature and probe sonication $(2$ minutes $\times 50 \mathrm{~W})$ to obtain clear DHE-sHDL. The final DHE concentration in peptide-DHE-sHDL was $0.5 \mathrm{mM}$. The LCAT assay was adapted from Homan et al. (2013) and performed in
384 -well black polystyrene plates in triplicate. Briefly, $8 \mu \mathrm{l}$ of different concentrations $(0,5,10,20,40,60$, and $100 \mu \mathrm{M})$ of DHE-sHDL (substrates) in assay buffer (PBS containing $1 \mathrm{mM}$ EDTA, $5 \mathrm{mM}$ $\beta$-mercaptoethanol, and $60 \mu \mathrm{M}$ albumin, $\mathrm{pH} 7.4)$ preheated to $37^{\circ} \mathrm{C}$ were incubated with $8 \mu \mathrm{l}$ of $5 \mu \mathrm{g} / \mathrm{ml}$ LCAT in dilution buffer (PBS with $1 \mathrm{mM}$ EDTA and $60 \mu \mathrm{M}$ albumin, $\mathrm{pH}$ 7.4) preheated to $37^{\circ} \mathrm{C}$ in triplicates. The plates were incubated at $37^{\circ} \mathrm{C}$ with gentle shaking (80 rpm/min) for different lengths of time (0, 10, and 20 minutes). Reactions were stopped by adding $4 \mu \mathrm{l}$ of stop solution $(3.75 \mathrm{IU} / \mathrm{ml}$ cholesterol oxidase) in PBS containing $1 \mathrm{mM}$ EDTA and 7\% Triton X100 . The plates were then incubated at $37^{\circ} \mathrm{C}$ with shaking $(80 \mathrm{rpm} /$ $\mathrm{min}$ ) for another hour to quench the fluorescence of unesterified DHE. The fluorescence was measured at an excitation wavelength of $325 \mathrm{~nm}$ and an emission wavelength of $425 \mathrm{~nm}$ using a plate-reader (SynergyTM NEO HTS Multi-Mode Microplate Reader; Bio-Tek). A standard curve was made by plotting the fluorescence of serially diluted DHEcontaining sHDL mixed with LCAT and using stop solution without $\mathrm{COx}$ versus the concentration (micromolar) of DHE. To calculate the concentration (micromolar) of DHE ester for each reaction, the background fluorescence $(0 \mu \mathrm{M}$ of $\mathrm{DHE})$ was subtracted from all fluorescence measurements and then divided by the slope (fluorescence per micromolar) of the above standard curve. To calculate $V_{\max }$ and $\mathrm{K}_{\mathrm{m}}$, the concentrations (micromolar) of DHE ester at different time points were plotted against time (hour), and the initial velocity $\left(\mathrm{V}_{0}\right.$, micromolar DHE-ester per hour) was the slope of the linear range of DHE-ester concentration versus time. The $V_{\max }$ and $\mathrm{K}_{\mathrm{m}}$ were obtained by plotting $\mathrm{V}_{0}$ versus DHE concentration and then analyzed by GraphPad Prism 7 (nonlinear regression, Michaelis-Menten model).

Plasma Peptide Stability. The in vitro stability of 22A, 21A, and 22A-P peptides was assessed by the addition of $2.5 \mu \mathrm{l} \mathrm{of} 10 \mathrm{mg} / \mathrm{ml}$ of a peptide to $97.5 \mu \mathrm{l}$ of fresh rat plasma (K2 EDTA; Innovative Research Inc). Immediately after the addition of peptide to plasma, $10 \mu \mathrm{l}$ of serum was removed to serve as a baseline and stored at $-20^{\circ} \mathrm{C}$. Samples were incubated at $37^{\circ} \mathrm{C}$ for 24 hours with shaking at $240 \mathrm{rpm}$. To determine peptide concentration at 0 and 24 hours post-plasma incubation, $10 \mu \mathrm{l}$ of plasma containing a peptide or working standard $(0-100 \mu \mathrm{g} / \mathrm{ml}$ ) was mixed with $2 \mu \mathrm{l}$ of $2.4 \mathrm{mg} / \mathrm{ml}$ internal standard (5A peptide) and $38 \mu \mathrm{l}$ of $\mathrm{H}_{2} \mathrm{O}$. Methanol $(200 \mu \mathrm{l})$ was added to precipitate plasma proteins. The mixture was vortexed for 10 seconds, centrifuged at $12,000 \mathrm{rpm}$ for 10 minutes, and the supernatant was collected for liquid chromatography-mass spectrometry (LC-MS) analysis. Samples were mixed (1:1 v/v) with LC-MS mobile phase (80:20 v/v $\mathrm{H}_{2} \mathrm{O}$ / acetonitrile, $0.1 \%$ formic acid) and analyzed on Waters Acquity UPLC equipped with QDa System using Acquity UPLC BEH C18 $1.7 \mu \mathrm{M}$ column for separation. The mobile phase consisted of (A) water containing $0.1 \% \mathrm{v} / \mathrm{v}$ formic acid and (B) acetonitrile containing $0.1 \% \mathrm{v} / \mathrm{v}$ formic acid. The mobile phase was delivered at $0.3 \mathrm{ml} / \mathrm{min}$ using a gradient elution of 20\%-80\% B during 0-1.5 minutes, and 80\%-20\% B during 1.5-3.5 minutes. Mass spectra were acquired in the positive ion mode with the mass range set at $m / z$ 150-1250. Data analysis was performed on Waters Empower software. The concentration of $22 \mathrm{~A}, 21 \mathrm{~A}$, or $22 \mathrm{~A}-\mathrm{P}$ peptide in each sample was determined from the standard curve.

Peptide Pharmacokinetics, Cholesterol Mobilization, and Esterification In Vivo. Healthy male Sprague-Dawley rats (8 weeks old) were purchased from Charles River Breeding Laboratories (Portage, MI) and were fed a standard rodent chow diet. To examine the impact of peptide composition on sHDL PK/PD properties, animals were randomly assigned to two groups ( $n=4$ /group) for 22A-POPC/ DPPC (22A-sHDL) and 22A-P-POPC/DPPC (22A-P-sHDL) administration. To examine the impact of lipid composition on sHDL PK/PD, animals were randomly assigned to four groups ( $n=3$ /group) for 22APOPC, 22A-DMPC, 22A-DPPC, and 22A-DSPC administration. All sHDL particles were prepared at 1:2 w/w peptide-to-phospholipid ratios, sterile-filtered, and characterized by DLS and GPC for size and purity prior to animal dosing. All animals were fasted overnight before sHDL dosing at $50 \mathrm{mg} / \mathrm{kg}$ (on the basis of peptide concentration) via 
tail vein injection. At each time point (predose, $0.25,0.5,1,2,4,8$, and 24 hours) blood samples (approx. $0.3 \mathrm{ml}$ ) were collected from the jugular vein to heparinized BD tubes (Franklin Lakes, NJ) and centrifuged at $10,000 \mathrm{rpm}$ for 10 minutes at $4^{\circ} \mathrm{C}$. The serum samples obtained were stored at $-20^{\circ} \mathrm{C}$ for further analysis.

The levels of plasma phospholipids (PL), total cholesterol (TC), and free cholesterol (FC) were determined enzymatically (Wako Chemicals, Richmond, VA) using a plate reader (Synergy ${ }^{\text {TM }}$ NEO HTS Multi-Mode Microplate Reader; Bio-Tek). Esterified cholesterol levels were calculated as the difference between TC and FC levels at each time point. Briefly, serum samples were diluted with PBS for TC and FC detection, or with MilliQ water for PL detection. Defined amounts of standards or diluted samples were transferred to 96 -well plates (50, 60 , and $20 \mu \mathrm{l}$ for TC, FC, and PL analyses, respectively), and assay reagents were added per manufacturer's instructions. The plates were gently shaken using an orbital shaker and incubated at $37^{\circ} \mathrm{C}$ for 5 minutes. The UV absorbance at $600 \mathrm{~nm}$ was measured by a Molecular Devices SpectraMax M3 plate reader (Sunnyvale, CA). Pharmacokinetic parameters were also obtained by noncompartmental analysis. The pharmacodynamic effect in each rat was determined as the area under the total effect curve (AUEC) using the trapezoidal rule. Secondary pharmacodynamic endpoints, maximal effect $\left(E_{\text {max }}\right)$, and time to $E_{\max }\left(T_{\max , E}\right)$, were also analyzed to compare pharmacodynamic effects.

Peptide (22A or 22A-P) concentration in serum was determined by LC-MS. The $10-\mu \mathrm{l}$ serum aliquots were combined with $10 \mu \mathrm{l}$ of $2.4 \mathrm{mg} /$

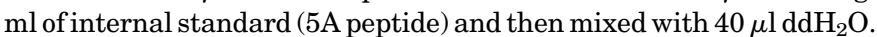
Working standard solutions $(0-100 \mu \mathrm{g} / \mathrm{ml})$ of $22 \mathrm{~A}$ and $22 \mathrm{~A}-\mathrm{P}$ were prepared as described above for plasma samples with the exception of the blank rat serum. Plasma proteins were precipitated by adding $180 \mu \mathrm{l}$ of methanol. After 5 minutes, the mixture was centrifuged $\left(12,000 \mathrm{rpm} \times 10\right.$ minutes, $\left.4^{\circ} \mathrm{C}\right)$ and $100 \mu \mathrm{l}$ of the supernatant was used for analysis. Each sample was analyzed by LC-MS as described above under Plasma Peptide Stability. Pharmacokinetic parameters such as maximum serum concentration $\left(C_{\max }\right)$, the area under the serum concentration-time curve $(A U C)$, elimination rate constant $(K)$, elimination half-life $\left(T_{1 / 2}\right)$, total clearance $(C L)$, and volume of distribution $\left(V_{d}\right)$ were obtained by noncompartmental analysis.

Remodeling of Endogenous Lipoproteins by sHDL in Human Plasma. Remodeling of endogenous lipoproteins in human plasma by sHDL was assessed by one-dimensional native polyacrylamide gel electrophoresis (1-D native PAGE) following sHDL incubation in plasma. Various sHDL (22A-POPC, 22A-DMPC, 22A-DPPC, 22A-DSPC, 21A-sHDL, 22A-sHDL, and 22A-P-sHDL) at $1 \mathrm{mg} / \mathrm{ml}$ concentration were incubated at $37^{\circ} \mathrm{C}$ for 1 hour with shaking at $300 \mathrm{rpm}$. The subclasses of HDL were separated by size using 1-D native PAGE and visualized by Western blot using the anti-ApoA-I antibody. Briefly, samples were subjected to electrophoresis using Tris-borateEDTA (TBE) gradient (4\%-20\%) acrylamide minigels. For each well, $10 \mu \mathrm{l}$ of human plasma incubated with or without sHDL was mixed with $10 \mu \mathrm{l}$ of $2 \times \mathrm{TBE}$ sample buffer, and $6 \mu \mathrm{l}$ of the resulting mixtures were loaded per well. Gels were run at $200 \mathrm{~V}$. Proteins were transferred to polyvinylidene difluoride membrane and incubated overnight with the anti-human ApoA-I-HRP conjugated antibody. Proteins were visualized with the enhanced chemiluminescent substrate on Protein Simple FluorChem M imaging system (San Jose, CA).

Statistical Analysis. Significance of difference was determined by Student's $t$ test for comparing two groups or by one-way ANOVA with Dunnett's post-hoc test for comparing multiple groups with $22 \mathrm{~A}$ peptide or 22A-DMPC as the control. All samples were performed in triplicate and error bars were reported as a S.E.M. unless noted otherwise. $P<0.05$ was considered statistically significant.

\section{Results}

Design of ApoA-I Peptides with Improved Plasma Stability. Helical wheel plots for 22A, 22A-P, and 21A were generated to assess the amphipathic nature of each peptide.
The hydrophobic amino acids clustered on one side of the helix suggested an amphipathic orientation of each peptide (Table 1). The three-dimensional hydrophobic moment vector calculations were performed to predict and compare the interactions of each peptide with lipid membranes. It was determined that the hydrophobic moment vectors were almost identical, with an average of $10.3 \pm 0.7 \mathrm{~A} * \mathrm{kT} / \mathrm{e}$. Additionally, we used an online server to determine the helix stability $\left(\Delta \mathrm{G}_{\mathrm{hel}}\right)$, transfer energy from water to membrane $\left(\Delta \mathrm{G}_{\text {trans }}\right)$, and orientation of each peptide in the membrane (penetration depth, D). Again, we did not find large differences in any of the aforementioned parameters, suggesting that the absence of the terminal lysine in $21 \mathrm{~A}$ or the addition of proline in $22 \mathrm{~A}-\mathrm{P}$ did not change the physical properties of these peptides compared with $22 \mathrm{~A}$. Next, we compared the plasma stability of $22 \mathrm{~A}, 22 \mathrm{~A}-\mathrm{P}$, and $21 \mathrm{~A}$ as well as their abilities to bind lipid and form sHDL particles. We found that whereas 22A degrades in plasma with only $48 \%$ of intact peptide remaining after a 24 -hour incubation at $37^{\circ} \mathrm{C}$, both $22 \mathrm{~A}-\mathrm{P}$ and $21 \mathrm{~A}$ were significantly more stable, with $89 \%$ and $97 \%$ of intact peptide remaining, respectively. These results suggest that the plasma stability of $22 \mathrm{~A}$ peptide can be greatly improved by the addition of a bulky proline, while computed lipid binding properties remained relatively unchanged.

Preparation and Characterization of sHDL Particles. We next evaluated the ability of 21A, 22A, and 22A-P peptide to form homogeneous sHDL particles. Synthetic HDL particles were prepared by combining $22 \mathrm{~A}, 21 \mathrm{~A}$, or $22 \mathrm{~A}-\mathrm{P}$ peptide with DMPC at 1:2 w/w peptide/lipid ratio, which was previously used in the ETC-642 formulation, resulting in the formation of homogeneous sHDL particles with approx. 10-nm size (Li et al., 2015; Tang et al., 2017). All three peptides formed homogeneous sHDL particles with average diameters of approx. $10 \mathrm{~nm}$ and a narrow polydispersity index of $0.17 \pm$ 0.04 as determined by DLS (Fig. 1A). Purity and homogeneity of sHDL size distribution were evaluated by GPC (Fig. 1B). All three sHDL were over $98 \%$ pure, and negligible levels of the free peptide $(<2 \%)$ were observed at the retention time of approx. 11 minutes (Supplemental Table 1). The binding of a peptide to phospholipid was also confirmed by increased helicity of $22 \mathrm{~A}, 21 \mathrm{~A}$, and 22A-P in sHDL particles $(94 \%, 91 \%$, and $82 \%$ ) relative to the free peptide $(77 \%, 79 \%$, and $77 \%)$ as measured by CD.

We also altered the phospholipid composition of $22 \mathrm{~A}$ sHDL to study its impact in vitro and in vivo. We chose four lipids with different physical properties, such as transition temperature and affinity for cholesterol (DSPC $>$ DPPC $>$ DMPC $>$ POPC) (Small, 1986; Ramstedt and Slotte, 1999; Ohvo-Rekilä et al., 2002). The sHDL complexes were formed by combining $22 \mathrm{~A}$ peptide with individual lipids at 1:2 w/w ratio using the colyophilization method. All were highly homogeneous with an average hydrodynamic diameter ranging between 8.3 and $10.5 \mathrm{~nm}$, low polydispersity index, and GPC purity greater than $95 \%$ (Fig. 1, C and D). The purity, size, and polydispersity levels of sHDL are summarized in Supplemental Table 1. The DMPC, DPPC, and DSPC-based sHDL had smaller hydrodynamic diameters, higher GPC purities, and sharper GPC peaks relative to $22 \mathrm{~A}-\mathrm{POPC}$. The presence of free peptide $(<1 \%$, retention time approx. 11.3 minutes $)$ and liposome impurities $(<2 \%$, retention time approx. 5.5 minutes) were observed for 22A-POPC, which also had the largest average particle size and broadest size distribution. Because POPC 
TABLE 1

Biophysical characterization of peptides

\begin{tabular}{|c|c|c|c|}
\hline Peptide Name & $22 \mathrm{~A}$ & $21 \mathrm{~A}$ & 22A-P \\
\hline Sequence & PVLDLFRELLNELLEALKQKLK & PVLDLFRELLNELLEALKQKL & PVLDLFRELLNELLEALKQKLKP \\
\hline $\begin{array}{l}\text { Hydrophobic moment vector }(\mathrm{A} * \mathrm{kT} / \mathrm{e})^{b} \\
\Delta \mathrm{G}_{\mathrm{hel}}(\mathrm{kcal} / \mathrm{mol})^{c} \\
\Delta \mathrm{G}_{\mathrm{tran}}(\mathrm{kcal} / \mathrm{mol})^{\mathrm{c}} \\
\mathrm{D}(\mathrm{A})^{\mathrm{c}} \\
\text { Helical content of lipid-free peptide }(\%)^{d} \\
\text { Helical content of lipid-bound peptide }(\%)^{\mathrm{d}} \\
\text { Peptide plasma stability }(\%)^{e}\end{array}$ & $\begin{array}{c}11.1 \\
-19.8 \\
-14.7 \\
11.8 \pm 3.6 \\
76.6 \\
93.9 \\
48.4 \pm 10.6\end{array}$ & $\begin{array}{c}10.0 \\
-19.4 \\
-13.4 \\
8.1 \pm 4.6 \\
79.0 \\
90.9 \\
96.8 \pm 5.4\end{array}$ & $\begin{array}{c}9.9 \\
-19.8 \\
-14.7 \\
11.8 \pm 3.6 \\
76.5 \\
81.6 \\
89.3 \pm 12.5\end{array}$ \\
\hline
\end{tabular}

${ }^{a}$ Helical wheel plots were generated using the online tool called Helixator, where hydrophobic amino acids were highlighted in black.

${ }^{b}$ Hydrophobic moments were calculated by the $3 \mathrm{D}$ Hydrophobic Moment Vector Calculator.

${ }^{c}$ Helix stability $\left(\Delta \mathrm{G}_{\text {hel }}\right)$, transfer energy from water to membrane $\left(\Delta \mathrm{G}_{\text {tran }}\right)$, and tilt angle in membranes were predicted by Folding of Membrane-Associated Peptide (FMAP) server for $22 \mathrm{~A}, 21 \mathrm{~A}$, and $22 \mathrm{~A}-\mathrm{P}$ peptide sequences.

${ }^{d}$ Helical content of lipid-free and lipid-bound peptides was determined by circular dichroism.

${ }^{e}$ Peptide stability in rat plasma was determined by LC-MS shown as percent remaining peptide following 24 -h incubation at $37^{\circ} \mathrm{C}$ ( $n=3$, mean \pm S.D.).

has the lowest $\mathrm{T}_{\mathrm{m}}$ of $-2^{\circ} \mathrm{C}$, it exists in a fluid gel state at room temperature, which probably impacted 22A-POPC stability.

Lipid Composition of sHDL Impacts Macrophage Cholesterol Efflux. We next examined how the C-terminal modifications in 22A-P and 21A impact cholesterol efflux abilities relative to $22 \mathrm{~A}$, either as free peptides or reconstituted into sHDL. Radioactive cholesterol was loaded into the BHK cell line stably transfected with human ABCA1 transporter, and peptides were incubated with the cells at $0,0.01$, 0.03 , and $0.1 \mathrm{mg} / \mathrm{ml}$. The same experiment was repeated using the control BHK-Mock cell line to assess cholesterol efflux by passive diffusion. The nonspecific cholesterol efflux values were then subtracted from the data obtained for each peptide with ABCA1-transfected cells to reveal receptor-specific cholesterol efflux (Fig. 2A). All three peptides exhibited concentration-dependent cholesterol efflux, with only minor differences $(<5 \%)$ observed, indicating that modifications at the $\mathrm{C}$ terminal end of $22 \mathrm{~A}$ did not affect lipid binding and ABCA1 transporter interaction. The three peptide sequences were then assembled into sHDL and their abilities to efflux cholesterol from macrophages were examined in the RAW 264.7 cell line (Fig. 2B). As with free peptide, concentration-dependent
A
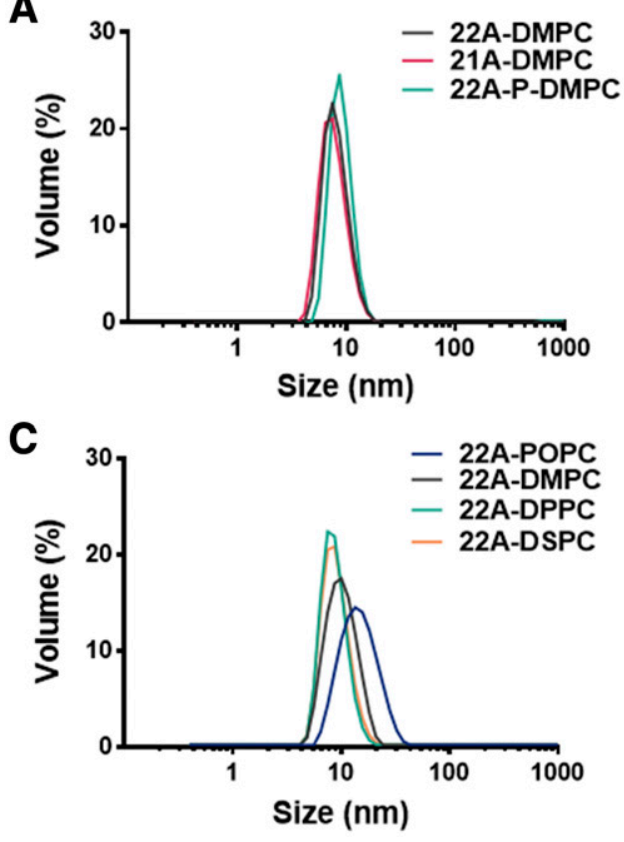

B

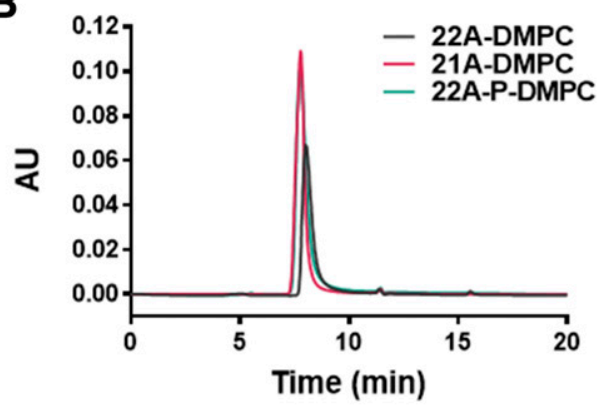

D

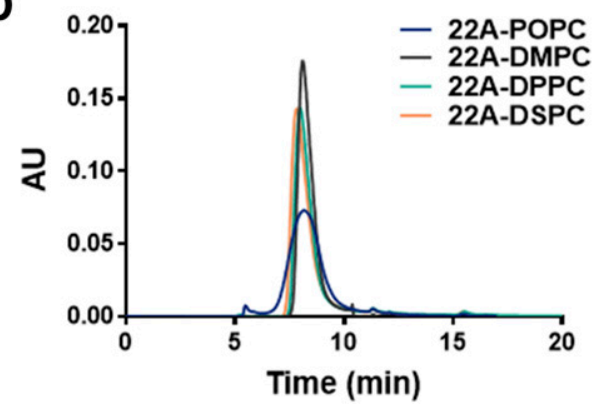

Fig. 1. Size distribution and purity of sHDL prepared with various peptide (A and $\mathrm{B}$ ) and phospholipid (C and $\mathrm{D}$ ) compositions. The size was determined by dynamic light scattering (A and $\mathrm{C}$ ) and purity was determined by GPC (B and D). 
A

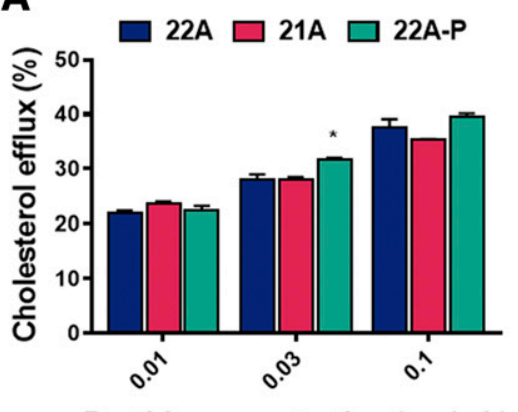

Peptide concentration $(\mathrm{mg} / \mathrm{mL})$
B

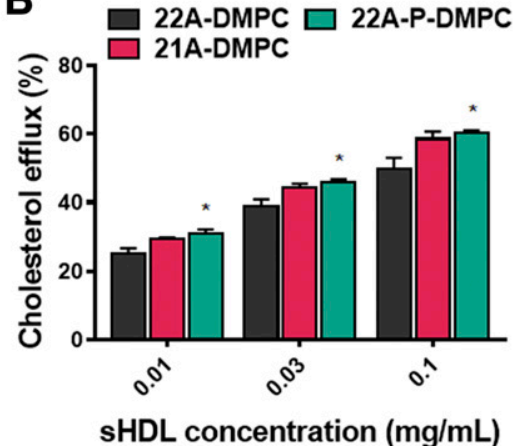

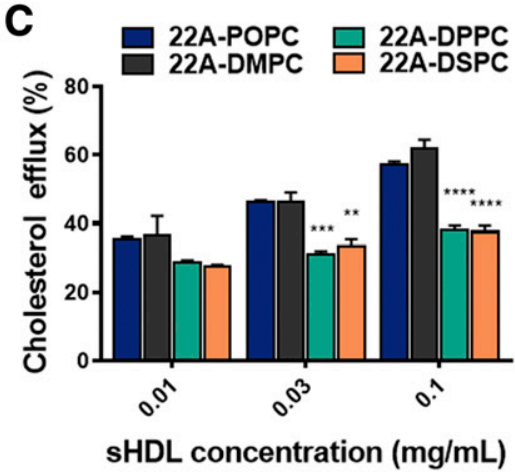

Fig. 2. Effect of peptides and sHDL on cholesterol efflux. Free peptides (22A, 21A, 22A-P) were used to efflux cholesterol from BHK cells stably transfected with ABCA1 transporter (A), and sHDL (22A-DMPC, 21A-DMPC, 22A-P-DMPC and 22A-POPC, 22A-DMPC, 22A-DPPC, 22A-DSPC) were used to efflux cholesterol from RAW 264.7 macrophage cells (B and C) at $0.01,0.03$, and $0.1 \mathrm{mg} / \mathrm{ml}$ for 18 hours. The contribution of ABCA1 transporter was determined by subtracting efflux values of Mock-transfected cell line from ABCA1-transfected cell line $(n=3$, mean \pm S.E.M.). Statistical differences were compared with 22A peptide or 22A-DMPC with one-way ANOVA with Dunnett's post-hoc test. $P<0.05$ was considered statistically significant $* P<0.05 ; * * P<0.01 ; * * * P<0.001 ; * * * P<0.0001$.

cholesterol efflux was observed with only minor differences $(<5 \%)$ at concentrations tested.

To explore the impact of the phospholipid component of sHDL on macrophage cholesterol efflux, 22A-POPC, 22ADMPC, 22A-DPPC, and 22-DSPC were incubated with RAW 264.7 cells. Saturated long-chain-length phospholipids such as DPPC and DSPC have higher physical binding affinity to cholesterol relative to POPC and DMPC (Ramstedt and Slotte, 1999; Ohvo-Rekilä et al., 2002). However, the transition temperature of POPC and DMPC is below $37^{\circ} \mathrm{C}$, thus the phospholipid bilayer is in a liquid crystal state at physiologic temperature, facilitating cholesterol partitioning in these sHDL particles at the cell culture conditions (Davidson et al., 1995). As expected, we observed greater cholesterol efflux to POPC and DMPC-based sHDL relative to DPPC and DSPC-based sHDL probably owing to differences in lipid fluidity at $37^{\circ} \mathrm{C}$ (Fig. 2C). Whereas 22A-DPPC and 22A-DSPC did not have any significant differences in cholesterol efflux as concentration increased, 22A-POPC and 22A-DMPC showed sHDL concentration-dependent increases in cholesterol efflux. Interestingly, 22A-DMPC showed the most effective cholesterol efflux capability from as low as $36 \%$ at $0.01 \mathrm{mg} / \mathrm{ml}$ to as high as $61.8 \%$ at $0.1 \mathrm{mg} / \mathrm{ml}$ concentration. Membrane transporters such as ABCG1/G4 and SR-BI are known to play a major role in cholesterol efflux to HDL rather than lipid-free protein and may contribute to the differences seen between sHDL in our study (Krieger, 1999; Wang et al., 2004). Taken together, the phospholipid composition of sHDL appears to play a significant role in cholesterol efflux from macrophages in cell culture.

Peptide and Lipid Composition Both Impact sHDL Interaction with LCAT. Following cholesterol efflux from macrophages, sHDL particles interact in plasma with LCAT (Asztalos et al., 2007). It is expected that both lipid and peptide composition of sHDL will have an effect on LCAT interaction. The fluidity of the HDL lipid membrane determines the ease of LCAT binding to HDL particles (Soutar et al., 1975). It has been shown that LCAT interaction with ApoA-I is critical for LCAT activation, especially for the facilitation of acyltransferase activity (Sorci-Thomas et al., 1993). Whereas some ApoA-I mimetic peptides have LCAT activation ability similar to full-length ApoA-I, others fail to facilitate EC formation (Anantharamaiah et al., 1990; Dasseux et al., 1999; Datta et al., 2001). The presence of positively charged clusters on the C-terminus, presence of hydrophobic amino acids at positions $3,6,9$, and 10 , and net peptide charge of zero are believed to be critical to the high LCAT activation ability of 22A (Dasseux et al., 1999, 2004). To examine how modification of $22 \mathrm{~A}$ and lipid composition of sHDL impact phospholipase A2 activity of LCAT, sHDL were coincubated with enzyme, and the kinetics of reduction of phospholipid concentration was monitored by LC-MS. We found that small changes in 22A sequence had only limited impact on phospholipase A2 activity (lipolysis) activity (Fig. 3A), indicating that LCAT activation by a C-terminal positive cluster on the peptide might not be critical for lipase activity. In contrast, the sHDL lipid composition had profound effect on LCAT-catalyzed phospholipid lipolysis, with the rates of $0.08,0.08,0.01$, and 0.0 hour $^{-1}$ for 22A-POPC, 22A-DMPC, 2A-DPPC, and 22ADSPC, respectively. DSPC and DPPC, phospholipids with $\mathrm{T}_{\mathrm{m}}$ values above $37^{\circ} \mathrm{C}$, had minimal lipolysis probably owing to poor LCAT binding to sHDL, and thus, presumably, there was difficulty in the accessibility of substrate for the enzymatic reaction.

Next, we assessed the impact of peptide and lipid composition of SHDL on LCAT acyltransferase activity by incorporating a fluorescent cholesterol analog called dehydroergosterol and measuring the rate of sterol esterification by LCAT. Changes in C-terminus of 22A peptide had a significant effect on the acyltransferase activity with a 2.6 -fold decrease in $\mathrm{k}_{\text {cat }}$ upon the loss of lysine for 21A (Fig. 3C). The rate was only decreased by $30 \%$ for 22A-P-HDL. When 22A-sHDL was complexed with different compositions of phospholipids, acyltransferase activity of LCAT was the highest for 22A-POPC sHDL (Fig. 3D). Sterol esterification was only limited for 22ADMPC sHDL, and no activity was detected for 22A-DPPC and 22A-DSPC. This trend was similar to the differences in phospholipase A2 activity observed for sHDL prepared with different lipids (POPC $\geq$ DMPC $>$ DPPC $>$ DSPC), following their general trends in $\mathrm{T}_{\mathrm{m}}$ and membrane fluidity. The Michaelis-Menten parameter estimates for the LCAT assay and goodness of fit are provided in Supplemental Table 2. The assay has significant run-to-run variability; however, the samples analyzed within a single experiment (either in Fig. 3C or Fig. 3D) can be compared with one other. 
A
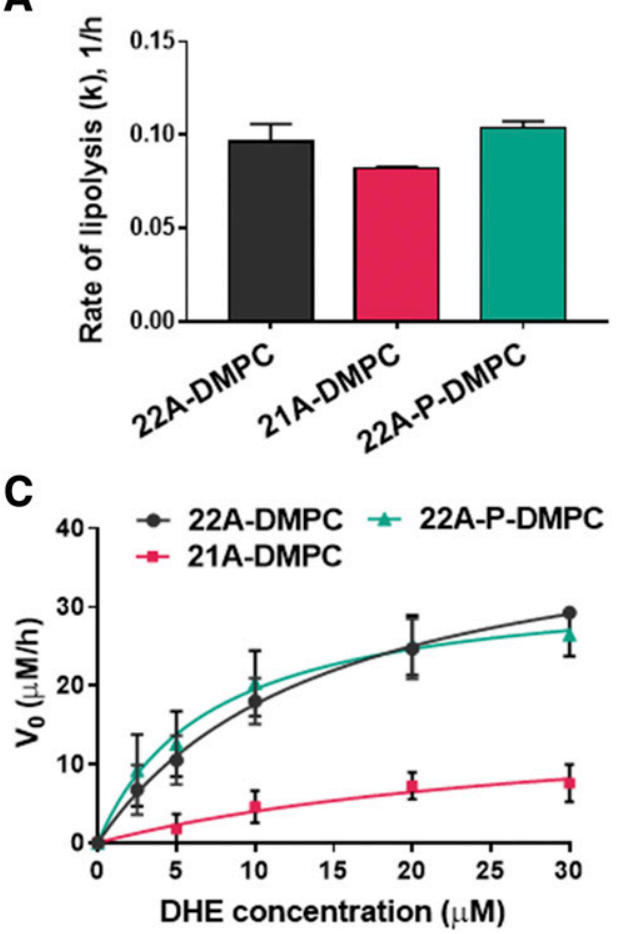

B
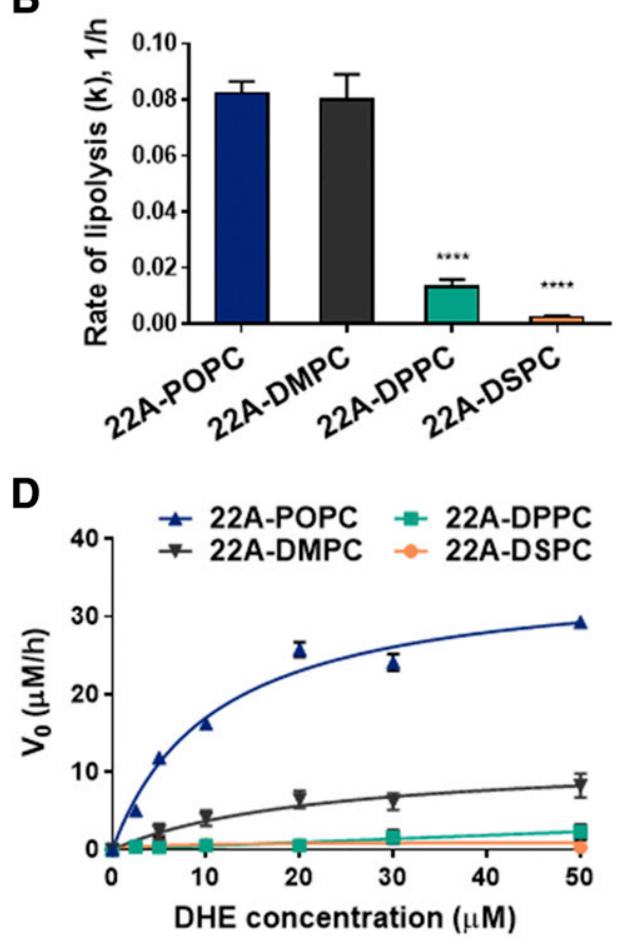

Fig. 3. Effect of peptide and phospholipid composition in SHDL on LCAT lipolysis and esterification rates. (A and $\mathrm{B}$ ) The rate of sHDL lipolysis was determined by incubating sHDL $(0.1 \mathrm{mg} / \mathrm{ml})$ prepared with variable peptide composition (22ADMPC，21A-DMPC，22A-P-DMPC) or variable phospholipid composition (22APOPC, 22A-DMPC, 22A-DPPC, 22ADSPC) with human rhLCAT $(15 \mu \mathrm{g} / \mathrm{ml})$ at $37^{\circ} \mathrm{C}$ for $0,5,15,30,60,90$, and 120 minutes. The concentration of phospholipid at each time point was determined by LC-MS and the rate of lipolysis calculated from the slope of the concentration of the starting material vs. time. LCAT esterification activity was measured for sHDL containing fluorescent cholesterol analog, dehydroergosterol (C and $\mathrm{D})$. The initial reaction rates $\left(\mathrm{V}_{0}\right)$ are plotted as a function of DHE concentration and the data were fitted into the Michaelis-Menten kinetic equation to calculate $\mathrm{V}_{\max }$ and $\mathrm{K}_{\mathrm{m}}(n=3$, mean \pm S.E.M.). Statistical differences were compared with 22A peptide or 22A-DMPC with one-way ANOVA and Dunnett's post-hoc test. $P<0.05$ was considered statistically significant $* * * * P<0.0001$.
Increase in Peptide Plasma Half-Life Has No Impact on Cholesterol Mobilization In Vivo. To evaluate whether in vitro peptide stability data correlates with in vivo peptide pharmacokinetics and cholesterol mobilization, we injected healthy Sprague Dawley rats with 22A-POPC/DPPC (22A-sHDL) or 22A-P-POPC/DPPC (22A-P-sHDL) at $50 \mathrm{mg} / \mathrm{kg}$ on the basis of peptide concentration in sHDL. Animal blood samples were collected before sHDL administration and at $0.25,0.5,1,2,4,8$, and 24 hours post-dose. The peptide concentrations in rat serum were determined using LC-MS (Fig. 4A). The noted stability of 22A-P when incubated with rat plasma translated well to in vivo settings, with an increase in peptide circulation half-life and exposure $\left(T_{1 / 2}=4.2\right.$ hours and $A U C=1721.0 \mathrm{mg} * \mathrm{~h} / \mathrm{dl})$ compared with $22 \mathrm{~A}\left(T_{1 / 2}=2.1\right.$ hours and $A U C=554.0 \mathrm{mg} * \mathrm{~h} / \mathrm{dl}$ ) (Table 2). We expected that these significant PK differences between the two peptides would translate into increased cholesterol mobilization by sHDL in vivo. Additionally, we anticipated that levels of esterified cholesterol would be different between two formulations in vivo on the basis of clear differences in LCATcatalyzed esterification between 22A-sHDL and 22A-P-sHDL in vitro. However, we saw no differences in cholesterol mobilization and esterification profiles between 22A-sHDL and 22A-P-sHDL in vivo as quantified by enzymatic assay of rat serum samples (Fig. 4, C and D; Table 2). Finally, if the sHDL particle stayed intact upon in vivo administration, we would expect to see longer circulation half-life for total phospholipids with 22A-P-sHDL relative to 22A-sHDL. To test this hypothesis, we determined phospholipid concentrations in plasma pre- and post-sHDL administration by an enzymatic assay. We observed no differences in phospholipid PK parameters between 22A-sHDL and 22A-P-sHDL, with the exception of $T_{1 / 2}: 22 \mathrm{~A}-\mathrm{P}-\mathrm{sHDL}$ (1.3 hours) showed significantly decreased $T_{1 / 2}$ compared with $22 \mathrm{~A}$-sHDL (1.8 hours) (Fig. 4B; Table 2). Altogether, these results suggest that the apparent differences in 22A-P and 22A stabilities in plasma and LCAT activation abilities had not resulted in measurable differences in cholesterol mobilization and esterification in vivo.

Lipid Composition of sHDL Impacts Cholesterol Mobilization In Vivo. To investigate the contribution of phospholipid composition of sHDL on cholesterol mobilization and esterification profiles in vivo, we administered 22APOPC, 22A-DMPC, 22A-DPPC, and 22A-DSPC sHDL to healthy Sprague Dawley rats. On the basis of cholesterol efflux from RAW 264.7 cells and LCAT-catalyzed esterification results in vitro, we were expecting to see higher cholesterol mobilization and esterification for POPC and DMPC-based sHDL in vivo. However, the results of in vivo administration of $50 \mathrm{mg} / \mathrm{kg}$ of sHDL were reversed, with 22A-DSPC showing significantly higher free cholesterol mobilization to the plasma compartment, as represented by the area under the total effect curve $\left(A U E C_{22 A-D S P C}=536.4 \mathrm{mg} * \mathrm{~h} / \mathrm{dl}\right)$, compared with lower values for the three other sHDL formulations $\left(A U E C_{22 A-P O P C}=79.4 \mathrm{mg} * \mathrm{~h} / \mathrm{dl}, A U E C_{22 A-D M P C}=126.5 \mathrm{mg} * \mathrm{~h} / \mathrm{dl}\right.$, and $A U E C_{22 A-D P P C}=215.0 \mathrm{mg} * \mathrm{~h} / \mathrm{dl}$ ) (Fig. 5; Table 3). Although the $C_{\max }$ of plasma EC was higher for DMPC-based sHDL, DSPC-based SHDL administration resulted in higher EC concentration at later time points and 3.5-fold greater $A U E C$ values relative to DMPC-based sHDL (Fig. 5D; Table 3). The differences between in vitro and in vivo results could be attributable to differences in lipid $\mathrm{T}_{\mathrm{m}}$ affecting the in vivo circulation time. Our in vivo data supports this hypothesis whereby phospholipids with higher transition temperatures such as DSPC $\left(\mathrm{T}_{\mathrm{m}}=55^{\circ} \mathrm{C}\right)$ show greater half-life and slower clearance than other phospholipids (Fig. 5B). Interestingly, the 22A peptide kinetics, such as plasma half-life after administration of sHDL in rats, did not follow phospholipid kinetics, similar to the differences in $\mathrm{PK}$ parameters between lipid and peptide obtained with 22A- and 22A-P-sHDL. The half-life of $22 \mathrm{~A}$ 
A

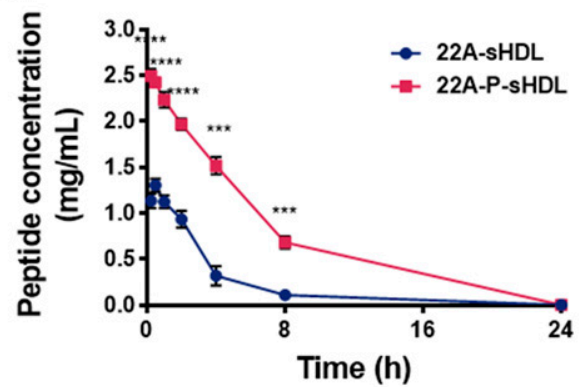

C

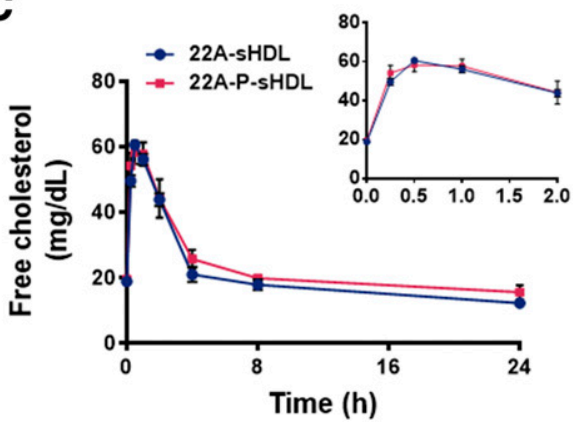

B

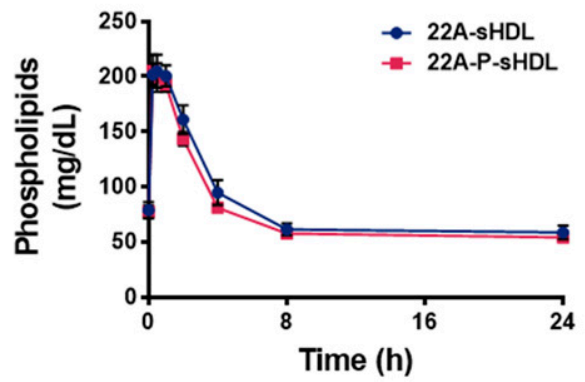

D

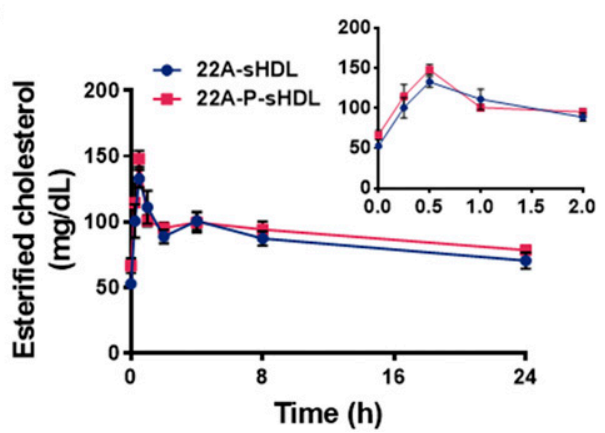

Fig. 4. Pharmacokinetic analysis of $22 \mathrm{~A}$ and 22A-P peptides (A) or total phospholipids (B) in rat serum. Pharmacodynamic assessment of free cholesterol (C) and esterified cholesterol (D) mobilization in rat serum. Healthy male Sprague-Dawley rats were given a single tail-vein injection of $50 \mathrm{mg} / \mathrm{kg}$ (on the basis of peptide) of 22A-POPC-DPPC or 22A-P-POPC-DPPC and blood samples were collected at predose and $0.25,0.5,1,2,4,8$, and 24 hour after sHDL administration. Serum concentrations of peptides were determined by LC-MS while concentrations of phospholipids, free cholesterol, and esterified cholesterol were measured enzymatically $(n=3)$. Statistical difference was compared with two-tailed Student's $t$ test. $P<$ 0.05 was considered statistically significant $* * P<0.01 ; * * * P<0.001 ; * * * * P<$ 0.0001 . after 22A-DSPC infusion was nearly identical to 22A-DMPC, 22A-POPC, and 22A-DPPC formulations (3.3, 3.0, 3.3, and 3.3 hours, respectively) (Table 3 ). Taken together, these results suggest that the ability of sHDL to mobilize cholesterol is strongly dependent on phospholipid composition and pharmacokinetics.

Remodeling of Endogenous HDL in Human Plasma. To assess how different compositions of sHDL facilitate the remodeling of endogenous lipoproteins, all sHDL particles were incubated with human plasma for 1 hour at $1 \mathrm{mg} / \mathrm{ml}$ peptide concentration. The HDL subfractions were separated

TABLE 2

Pharmacokinetic and pharmacodynamic parameters (\%CV) of peptide, total phospholipids, free cholesterol, and esterified cholesterol after $50 \mathrm{mg} / \mathrm{kg}$ doses of $22 \mathrm{~A}$-sHDL and 22A-P-sHDL treatments Data were shown as mean with CV\%.

\begin{tabular}{|c|c|c|c|}
\hline & \multirow{2}{*}{ Parameters } & \multicolumn{2}{|l|}{ Groups } \\
\hline & & 22A-sHDL & 22A-P-sHDL \\
\hline \multirow[t]{5}{*}{ Peptide } & $A U C(\mathrm{mg} * \mathrm{~h} / \mathrm{dl})$ & $554.0(22.0)$ & $1721.0(10.6)^{* * *}$ \\
\hline & $K\left(\mathrm{~h}^{-1}\right)$ & $0.3(25.8)$ & $0.2(12.0)$ \\
\hline & $T_{1 / 2}(\mathrm{~h})$ & $2.1(22.4)$ & $4.2(10.8)^{* * *}$ \\
\hline & $C L(\mathrm{dl} / \mathrm{h})$ & $2.3(21.8)$ & $0.7(10.9) * *$ \\
\hline & $V_{d}(\mathrm{dl})$ & $6.9(7.7)$ & $4.4(6.2) * *$ \\
\hline \multirow[t]{5}{*}{$P L$} & $A U C(\mathrm{mg} * \mathrm{~h} / \mathrm{dl})$ & $424.4(15.7)$ & 371.8 (23.5) \\
\hline & $K\left(\mathrm{~h}^{-1}\right)$ & $0.4(23.8)$ & $0.5(16.0)$ \\
\hline & $T_{1 / 2}(\mathrm{~h})$ & $1.8(18.8)$ & $1.3(11.4)^{*}$ \\
\hline & $C L(\mathrm{dl} / \mathrm{h})$ & $0.1(7.7)$ & $0.1(7.0)$ \\
\hline & $V_{d}(\mathrm{dl})$ & $0.1(21.4)$ & $0.1(2.1)$ \\
\hline \multirow[t]{3}{*}{$F C$} & $T_{\max , E}(\mathrm{~h})$ & $0.5(0.0)$ & $0.8(33.3)$ \\
\hline & $E_{\max }(\mathrm{mg} / \mathrm{dl})$ & $46.7(5.8)$ & $44.4(13.0)$ \\
\hline & $A U E C(\mathrm{mg} * \mathrm{~h} / \mathrm{dl})$ & $158.0(19.1)$ & $175.3(28.5)$ \\
\hline \multirow{3}{*}{$E C$} & $T_{\max , E}(\mathrm{~h})$ & $0.42(24.5)$ & $0.4(33.3)$ \\
\hline & $E_{\max }(\mathrm{mg} / \mathrm{dl})$ & $51.3(31.8)$ & $42.2(37.3)$ \\
\hline & $A U E C(\mathrm{mg} * \mathrm{~h} / \mathrm{dl})$ & $166.8(12.8)$ & $164.4(31.8)$ \\
\hline
\end{tabular}

$A U C$, the area under the curve; $C L$, total clearance; $E_{\text {max }}$, the maximum plasma concentration of different cholesterol species; $K$, elimination rate constant; $T_{1 / 2}$, the half-life of elimination; $T_{\max , E}$, time at which the $E_{\max }$ is observed; $V_{d}$, volume of distribution.

${ }^{*} P<0.05, * * P<0.01, * * * P<0.001$ by size using 1-D native PAGE and visualized by Western blot using anti-ApoA-I antibody (Fig. 6). We have confirmed that anti-ApoA-I antibody does not recognize 22A, 21A, or 22A-P; thus, we examined the impact of sHDL incubation on the remodeling of endogenous ApoA-I-containing proteins. Compared with human plasma control incubated with PBS, incubation of plasma with 22A-sHDL, 21A-sHDL, and 22A$\mathrm{P}$-sHDL resulted in the remodeling of endogenous HDL, as indicated by a diminished signal for the large $\alpha$-HDL and increased levels of lipid-poor ApoA-I. The effect of the phospholipid composition of sHDL on endogenous HDL remodeling was more prominent. Incubation of plasma with 22A-POPC resulted in a shift of HDL size from large $\alpha$-HDL to smaller pre- $\beta$ HDL. Incubation with $22 \mathrm{~A}-\mathrm{DMPC}$ showed the formation of even smaller pre- $\beta$ HDL particles with a band of lipid-free ApoA-I. In contrast, plasma incubation with 22ADSPC displayed very limited HDL remodeling, probably owing to the rigidity of the DSPC lipid membrane, and thus reduced the insertion of endogenous ApoA-I. The 22A-DPPC incubation with plasma resulted in some reduction of $\alpha$-HDL levels and formation of a predominant band of lipid-free ApoAI. Overall, the extent of HDL remodeling was significantly affected by the phospholipid composition of sHDL. The sHDL prepared with high $\mathrm{T}_{\mathrm{m}}$ phospholipids (22A-DPPC and 22ADSPC) exhibited higher plasma stability and less remodeling.

\section{Discussion}

Our previous studies have shown that upon intravenous administration of sHDL, 22A peptide becomes rapidly hydrolyzed into $21 \mathrm{~A}$ as a result of the loss of terminal lysine (Tang et al., 2017). The addition of C-terminal proline after the labile lysine in $22 \mathrm{~A}$ afforded a resistant-to-proteolysis peptide, as shown by incubation of $22 \mathrm{~A}-\mathrm{P}$ with rat plasma. The new peptide was successfully formulated into sHDL and dosed into rats. We expected to see longer circulation time and 
A

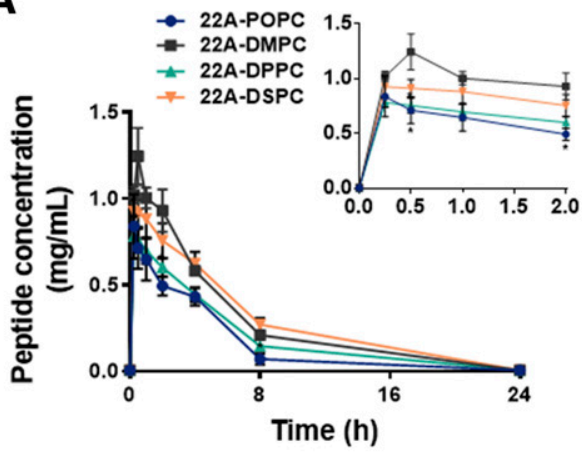

C

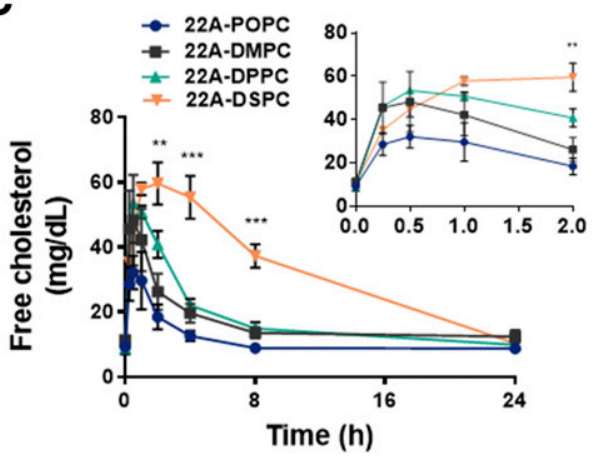

B

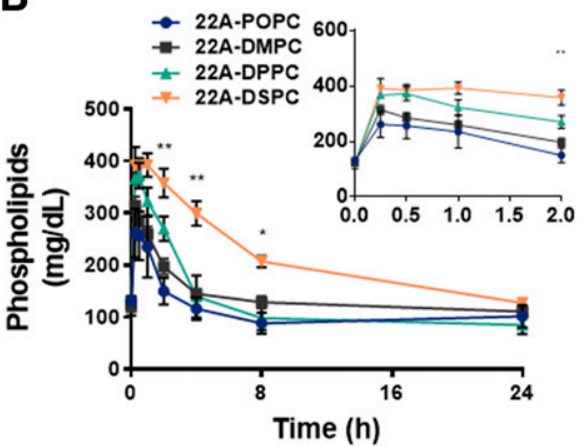

D

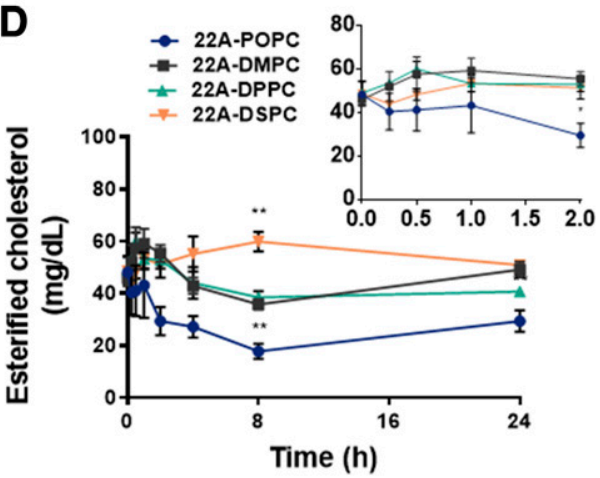

Fig. 5. Pharmacokinetic analysis of $22 \mathrm{~A}$ (A) and total phospholipids (B) in rat serum. Pharmacodynamic assessment of free cholesterol (C) and esterified cholesterol (D) mobilization in rat serum. Healthy male Sprague-Dawley rats were given a single tail-vein injection of $50 \mathrm{mg} / \mathrm{kg}$ (based on peptide) of 22A-POPC, 22A-DMPC, 22ADPPC, or 22A-DSPC, and blood samples were collected at pre-dose and $0.25,0.5,1$, $2,4,8$, and 24 hours after sHDL administration. Serum concentrations of peptides were determined by LC-MS, and concentrations of phospholipids, free cholesterol, and esterified cholesterol were measured enzymatically $(n=3)$. Statistical differences for 22A-phospholipid were compared with 22A-DMPC with one-way ANOVA analysis with Dunnett's post-hoc test. $P<0.05$ was considered statistically significant. $* P<0.05 ; * * P<0.01$ $* * * P<0.001$ correspondingly greater in vivo cholesterol mobilization for $22 \mathrm{~A}-\mathrm{P}-\mathrm{sHDL}$. As predicted in vitro, the half-life of $22 \mathrm{~A}-\mathrm{P}$ in animals was extended from 2.1 to 4.2 hours, and AUC for 22A$\mathrm{P}$ was nearly 3 -fold higher. However, the longer circulation time of 22A-P in vivo did not translate into a higher cholesterol mobilization profile by $22 \mathrm{~A}-\mathrm{P}-\mathrm{sHDL}$ compared with $22 \mathrm{~A}-$ sHDL. Furthermore, the AUCs of the phospholipid component of 22A-P-sHDL and 22A-sHDL were also not affected by the extension of the peptide half-life. When sHDL particles prepared with the same peptide $22 \mathrm{~A}$ and different phospholipids (POPC, DMPC, DPPC, or DSPC) were administered to rats, the peptide half-life was similar for all four formulations (3.2 \pm 0.1 hours). However, the phospholipid half-life varied dramatically, with DSPC circulating for 6.0 hours compared with 1.0-3.3 hours for other lipids. The trend of phospholipid circulation time for each sHDL formulation in animal serum was similar to that of cholesterol mobilization (22A-DSPC > 22A-DPPC, 22A-DMPC > 22A-POPC). Moreover, these findings are further supported by our HDL remodeling results showing only limited interaction of 22A-DSPC with endogenous HDL, which could extend circulation half-life. The limited interaction between sHDL and endogenous lipoproteins was

TABLE 3

Pharmacokinetic and pharmacodynamic parameters (\%CV) of $22 \mathrm{~A}$ peptide, total phospholipids, free cholesterol, and esterified cholesterol after $50 \mathrm{mg} / \mathrm{kg}$ doses of 22A-POPC, 22A-DMPC, 22A-DPPC, and 22A-DSPC sHDL treatments

Data were shown as mean with CV\%.

\begin{tabular}{|c|c|c|c|c|c|}
\hline & \multirow{2}{*}{ Parameters } & \multicolumn{4}{|c|}{ Groups } \\
\hline & & 22A-POPC & 22A-DMPC & 22A-DPPC & 22A-DSPC \\
\hline \multirow[t]{3}{*}{ Peptide } & $A U C(\mathrm{mg} * \mathrm{~h} / \mathrm{dl})$ & $364.0(8.6)^{* *}$ & $662.0(10.0)$ & $464.3(15.2)^{*}$ & $687.2(17.7)$ \\
\hline & $C L(\mathrm{dl} / \mathrm{h})$ & $5.6(11.8)^{* *}$ & $3.2(13.9)$ & $4.6(17.4)$ & $2.9(25.2)$ \\
\hline & $V_{d}(\mathrm{dl})$ & $27.1(16.7) * *$ & $14.0(15.5)$ & $21.9(19.0)$ & $13.7(29.1)$ \\
\hline \multirow[t]{2}{*}{$P L$} & $A U C(\mathrm{mg} * \mathrm{~h} / \mathrm{dl})$ & $371.6(29.0)$ & $703.2(23.2)$ & $934.9(22.8)$ & $2396(21.1)^{* * *}$ \\
\hline & $V_{d}(\mathrm{dl})$ & $0.2(29.8)$ & $0.3(23.3)$ & $0.2(45.9)$ & $0.1(16.0)^{*}$ \\
\hline \multirow[t]{3}{*}{$F C$} & $T_{\max E}(\mathrm{~h})$ & $0.7(35.4)$ & $0.4(28.3)$ & $0.7(35.4)$ & $1.3(35.4)^{*}$ \\
\hline & $E_{\max }(\mathrm{mg} / \mathrm{dl})$ & $25.8(36.8)$ & $37.6(19.8)$ & $44.8(5.1)$ & $51.5(15.3)$ \\
\hline & $A U E C(\mathrm{mg} * \mathrm{~h} / \mathrm{dl})$ & $79.4(33.9)$ & $126.5(10.0)$ & $215.0(20.9)$ & $536.4(19.1)^{* * *}$ \\
\hline \multirow[t]{3}{*}{$E C$} & $T_{\max E}(\mathrm{~h})$ & $0.5(70.7)$ & $0.8(28.3)$ & $0.9(84.3)$ & $6.7(28.3)^{* *}$ \\
\hline & $E_{\max }(\mathrm{mg} / \mathrm{dl})$ & $7.7(65.2)$ & $28.2(30.3)$ & $24.9(13.7)$ & $20.6(24.7)$ \\
\hline & $A U E C(\mathrm{mg} * \mathrm{~h} / \mathrm{dl})$ & $84.8(65.3)$ & $93.3(41.9)$ & $98.9(31.6)$ & $334.7(18.0)^{* *}$ \\
\hline
\end{tabular}

$A U C$, the area under the curve; $C L$, total clearance; $E_{\text {max }}$, the maximum plasma concentration of different cholesterol species; $K$, elimination rate constant; $T_{1 / 2}$, the half-life of elimination; $T_{\max E}$, time at which the $E_{\max }$ is observed; $V_{d}$, volume of distribution.

* $P<0.05 ; * P<0.01 ; * * * P<0.001$ 


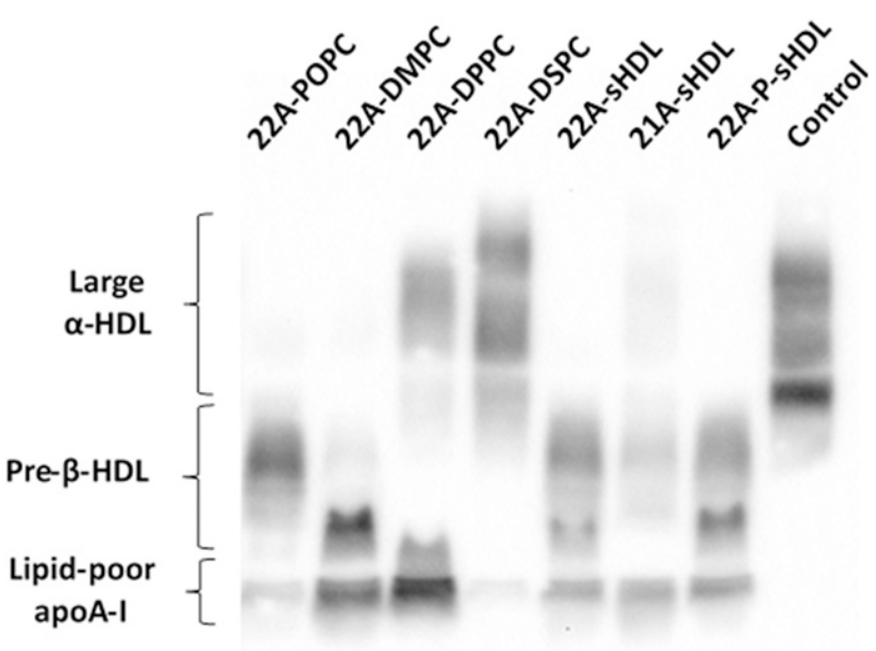

Fig. 6. Effect of sHDL incubation with human plasma on endogenous HDL remodeling. Various compositions of sHDL were incubated in human plasma at $1 \mathrm{mg} / \mathrm{ml}$ for 1 hour at $37^{\circ} \mathrm{C}$. Lipoproteins were separated by 1-D native PAGE electrophoresis and visualized by Western blot using antiApoA-I antibody.

probably the result of the difficulty of protein insertion in the gel membrane of DSPC $\left(\mathrm{T}_{\mathrm{m}}\right.$ of $55^{\circ} \mathrm{C}$, above physiologic temperature), as was observed in vitro for 22A-DSPC interaction with LCAT. Altogether, the data suggest that the pharmacokinetics of peptide and lipid components in sHDL are not interdependent, and original infused sHDL particles may dissociate or become remodeled upon administration in vivo. In addition, the phospholipid rather than peptide component in sHDL has a major impact on the ability to mobilize cholesterol in vivo. However, it is important to note that the peptide sequence modifications performed by us were rather minor. It has been shown that different sequences of ApoA-I mimetic peptides have measurable differences in cholesterol efflux in vitro and variable in vivo performance (Sethi et al., 2008; Wool et al., 2008; Amar et al., 2010; Bielicki et al., 2010).

Several other groups reported on the discordance between the PK of protein and phospholipid components of HDL in vivo. Xu et al. (2017) investigated the fate of ApoA-I protein and phospholipid after in vivo administration of HDL in an attempt to interrogate the validity of the RCT pathway. The investigators used ABCA1-derived ApoA-I-HDL with radiolabeled components and reported that phospholipids and ApoA-I enter different pathways for clearance in mice. The authors suggested that after the administration of radiolabeled ApoA-I-HDL, phospholipids were rapidly cleared by the liver and also transferred to LDL, whereas ApoA-I fused with endogenous HDL and circulated longer. CSL-112, the ApoA-I-soybean phosphatidylcholine sHDL product undergoing phase III clinical trial, is believed to undergo remodeling in human plasma with the generation of lipid-poor ApoA-I that is important for cholesterol efflux (Didichenko et al., 2016). Another sHDL product in clinical development, CER-001, composed from ApoA-I and primarily sphingomyelin, has shown differences, specifically longer half-life for phospholipid (approx. 46 hours) relative to ApoA-I (approx. 10 hours) (Keyserling et al., 2011; Tardy et al., 2014). We also found that incorporation of polyethylene glycol-modified lipids in ApoA-I peptide-based sHDL extended circulation time for lipids and prolonged the duration of mobilized cholesterol circulation but did not alter ApoA-I peptide PK (Li et al., 2018). Therefore, peptide and lipid components of sHDL may both contribute to cholesterol mobilization, not however as intact nanoparticles, but rather as separate entities via different mechanisms.

The phospholipid composition also impacted the ease of sHDL preparation, purity, and size of the resulting nanoparticles and their stability in vitro and in vivo. The sHDL prepared with DSPC, DPPC, and DMPC showed relatively similar narrow size distributions and high purities, whereas sHDL prepared with POPC appeared to be more heterogeneous, with larger average particle sizes and the presence of liposomal impurities. This relative difficulty of forming pure POPC-based sHDL particles has been reported previously and was attributed to the fluidity and instability of the POPC membrane at room temperature, which was well above the phospholipid's $\mathrm{T}_{\mathrm{m}}$ (Patel et al., 2019). The sHDL prepared with saturated lipids appeared to be more homogeneous and pure but required heating particles above lipid $\mathrm{T}_{\mathrm{m}}$ during preparation to facilitate ApoA-I peptide-lipid binding. In addition, the presence of unsaturated double bonds in lipids such as POPC could result in phospholipid oxidation, although this phenomenon was not investigated in this study.

Interestingly, we also observed a discordance between in vitro and in vivo results for sHDL prepared with different phospholipids and peptides. The in vitro trends for higher cholesterol efflux and superior ability to activate LCAT for 22A-POPC and 22A-DMPC did not translate into higher cholesterol mobilization and esterification in vivo. The free cholesterol mobilization and circulation time appear to have been closely following the circulation time of phospholipids, with the longer circulating saturated DSPC exhibiting higher $C_{\max }$ for FC mobilization and AUEC. Thus, the ease of cholesterol incorporation in unsaturated 22A-POPC becomes of limited significance in vivo owing to rapid elimination of POPC. The esterification seems to follow the same trend, as faster LCAT-catalyzed lipolysis and sterol esterification did not translate to greater $C_{\max }$ and $A U E C$ for EC in vivo. However, it is important to point out that the actual rate of EC formation and LCAT activation in vivo was not directly measured in this study and will require additional experiments as described by Turner et al. (2012). The stability of $22 \mathrm{~A}-\mathrm{P}$ is greatly improved in vivo relative to $22 \mathrm{~A}$; however, phospholipid PK appeared to be unchanged and cholesterol mobilization followed phospholipid PK. One of the explanations for this may be that both $22 \mathrm{~A}$ and $22 \mathrm{~A}-\mathrm{P}$ are capable of forming sHDL in vitro and maintaining sHDL stability in vivo, as the structures of all three peptides used by us were very similar. It is also important to point out that other groups had seen discordance between showing some structure-activity relationship for ApoA-I peptides in vitro and seeing no statistical differences in their pharmacological effects in vivo (Ditiatkovski et al., 2017).

Our data support the complexity of RCT and highlights that both ApoA-I protein/peptide and lipid components of sHDL contribute to the RCT pathway. The study also highlights that the phospholipid composition of sHDL is the driving force for cholesterol mobilization in vivo, and we plan to further examine whether higher cholesterol mobilization for sHDL composed of saturated lipids would lead to greater antiatherosclerosis effect in a murine model of the disease. 


\section{Acknowledgments}

We would like to thank MedImmune Corporation for providing recombinant LCAT and Dr. Alan Remaley (NIH) for providing BHK-MOCK and BHK-ABCA1 cell lines.

\section{Authorship Contributions}

Participated in research design: Fawaz, Kim, Tesmer, Schwendeman.

Conducted experiments: Fawaz, Kim, Ming, Xia, Olsen, Pogozheva. Performed data analysis: Fawaz, Kim, Li, Schwendeman.

Wrote or contributed to the writing of the manuscript: Fawaz, Kim, Pogozheva, Tesmer, Schwendeman.

\section{References}

Amar MJ, D’Souza W, Turner S, Demosky S, Sviridov D, Stonik J, Luchoomun J, Voogt J, Hellerstein M, Sviridov D, et al. (2010) 5A apolipoprotein mimetic peptide promotes cholesterol efflux and reduces atherosclerosis in mice. J Pharmacol Exp Ther 334:634-641.

Anantharamaiah GM, Venkatachalapathi YV, Brouillette CG, and Segrest JP (1990) Use of synthetic peptide analogues to localize lecithin:cholesterol acyltransferase activating domain in apolipoprotein A-I. Arteriosclerosis 10:95-105.

Andrews J, Janssan A, Nguyen T, Pisaniello AD, Scherer DJ, Kastelein JJP, Merkely B, Nissen SE, Ray K, Schwartz GG, et al. (2017) Effect of serial infusions of reconstituted high-density lipoprotein (CER-001) on coronary atherosclerosis: rationale and design of the CARAT study. Cardiovasc Diagn Ther 7:45-51.

Assmann G, Schmitz G, Donath N, and Lekim D (1978) Phosphatidylcholine substrate specificity of lecithin:cholesterol acyltransferase. Scand J Clin Lab Invest Suppl 150:16-20.

Asztalos BF, Schaefer EJ, Horvath KV, Yamashita S, Miller M, Franceschini G, and Calabresi L (2007) Role of LCAT in HDL remodeling: investigation of LCAT deficiency states. J Lipid Res 48:592-599.

Bielicki JK, Zhang H, Cortez Y, Zheng Y, Narayanaswami V, Patel A, Johansson J, and Azhar S (2010) A new HDL mimetic peptide that stimulates cellular choles terol efflux with high efficiency greatly reduces atherosclerosis in mice. J Lipid Res 51:1496-1503.

Bolin DJ and Jonas A (1996) Sphingomyelin inhibits the lecithin-cholesterol acyltransferase reaction with reconstituted high density lipoproteins by decreasing enzyme binding. J Biol Chem 271:19152-19158.

Dasseux J, Sekul R, Büttner K, Cornut I, Metz G, and Dufourcq J (2004) inventors. Multimeric Apoa-I agonist compounds. U.S. patent 6,7533,13 B1. 2004 Jun 22.

Dasseux J-L, Sekul R, Buttner K, Cornut I, Metz G, and Dufourcq J (1999) inventors, Esperion Therapeutics Inc, assignee. Apolipoprotein AI agonists and their use to treat dyslipidemic disorders. U.S. patent 09/865,989. 1999 Dec 17

Datta G, Chaddha M, Hama S, Navab M, Fogelman AM, Garber DW, Mishra VK, Epand RM, Epand RF, Lund-Katz S, et al. (2001) Effects of increasing hydrophobicity on the physical-chemical and biological properties of a class A amphipathic helical peptide. J Lipid Res 42:1096-1104.

Davidson WS, Gillotte KL, Lund-Katz S, Johnson WJ, Rothblat GH, and Phillips MC (1995) The effect of high density lipoprotein phospholipid acyl chain composition on the efflux of cellular free cholesterol. J Biol Chem 270:5882-5890.

Di Bartolo BA, Nicholls SJ, Bao S, Rye K-A, Heather AK, Barter PJ, and Bursill C (2011) The apolipoprotein A-I mimetic peptide ETC-642 exhibits antiinflammatory properties that are comparable to high density lipoproteins. Atherosclerosis 217:395-400.

Didichenko SA, Navdaev AV, Cukier AMO, Gille A, Schuetz P, Spycher MO, Thérond P, Chapman MJ, Kontush A, and Wright SD (2016) Enhanced HDL functionality in small HDL species produced upon remodeling of HDL by reconstituted HDL, CSL112: effects on cholesterol efflux, anti-inflammatory and antioxidative activity. Circ Res 119:751-763.

Ditiatkovski M, Palsson J, Chin-Dusting J, Remaley AT, and Sviridov D (2017) Apolipoprotein A-I mimetic peptides: discordance between in vitro and in vivo properties-brief report. Arterioscler Thromb Vasc Biol 37:1301-1306.

Homan R, Esmaeil N, Mendelsohn L, and Kato GJ (2013) A fluorescence method to detect and quantitate sterol esterification by lecithin:cholesterol acyltransferase. Anal Biochem 441:80-86.

Keyserling CH, Hunt TL, Klepp HM, Scott RA, Barbaras R, Schwendeman A, Lalwani N, and Dasseux J-L (2011) CER-001, a synthetic HDL-mimetic, safely mobilizes cholesterol in healthy dyslipidemic volunteers (Abstract). Circulation 124:15525.

Khan M, Drake S, Crockatt J, and Dasseux J (2003) Single-dose intravenous infusion of ETC-642, a 22-Mer ApoA-I analogue and phospholipids complex, elevates HDL$\mathrm{C}$ in atherosclerosis patients. Circulation 108:563-564.

Krieger M (1999) Charting the fate of the "good cholesterol": identification and characterization of the high-density lipoprotein receptor SR-BI. Annu Rev Biochem 68:523-558.

Li D, Fawaz MV, Morin EE, Ming R, Sviridov D, Tang J, Ackermann R, Olsen K, Remaley AT, and Schwendeman A (2018) Effect of synthetic high density lipoproteins modification with polyethylene glycol on pharmacokinetics and pharmacodynamics. Mol Pharm 15:83-96.

Li D, Gordon S, Schwendeman A, and Remaley AT (2015) Apolipoprotein mimetic peptides for stimulating cholesterol efflux, in Apolipoprotein Mimetics in the Management of Human Disease (Anantharamaiah GM and Goldberg D eds) pp 29-42, Springer, New York

Lomize AL, Lomize MA, Krolicki SR, and Pogozheva ID (2017) Membranome: a database for proteome-wide analysis of single-pass membrane proteins. Nucleic Acids Res 45 (D1):D250-D255.
Lomize MA, Pogozheva ID, Joo H, Mosberg HI, and Lomize AL (2012) OPM database and PPM web server: resources for positioning of proteins in membranes. Nucleic Acids Res 40:D370-D376.

Miles J, Khan M, Painchaud C, Lalwani N, Drake S, and Dasseux J (2004) P105 single-dose tolerability, pharmacokinetics, and cholesterol mobilization in Hdl-c fraction following intravenous administration of Etc-642, a 22-mer Apoa-i analogue and phospholipids complex, in atherosclerosis patients (Abstract). Arterioscler Thromb Vasc Biol J Am Hear Assoc 24:E19.

Navab M, Anantharamaiah GM, Reddy ST, and Fogelman AM (2006) Apolipoprotein A-I mimetic peptides and their role in atherosclerosis prevention. Nat Clin Pract Cardiovasc Med 3:540-547.

Navab M, Anantharamaiah GM, Hama S, Hough G, Reddy ST, Frank JS, Garber DW, Handattu S, and Fogelman AM (2005a) D-4F and statins synergize to render HDL antiinflammatory in mice and monkeys and cause lesion regression in old apolipoprotein E-null mice. Arterioscler Thromb Vasc Biol 25:1426-1432.

Navab M, Anantharamaiah GMM, Reddy ST, Hama S, Hough G, Grijalva VR, Yu N, Ansell BJ, Datta G, Garber DW, et al. (2005b) Apolipoprotein A-I mimetic peptides. Arterioscler Thromb Vasc Biol 25:1325-1331.

Nicholls SJ, Andrews J, Kastelein JJP, Merkely B, Nissen SE, Ray KK, Schwartz GG, Worthley SG, Keyserling C, Dasseux J-L, et al. (2018) Effect of serial infusions of CER-001, a pre- $\beta$ high-density lipoprotein mimetic, on coronary atherosclerosis in patients following acute coronary syndromes in the CER-001 atherosclerosis regression acute coronary syndrome trial: a randomized clinical trial. JAMA Cardiol 3:815-822.

Nissen SE, Tsunoda T, Tuzcu EM, Schoenhagen P, Cooper CJ, Yasin M, Eaton GM Lauer MA, Sheldon WS, Grines CL, et al. (2003) Effect of recombinant ApoA-I Milano on coronary atherosclerosis in patients with acute coronary syndromes: a randomized controlled trial. JAMA 290:2292-2300.

Ohvo-Rekilä H, Ramstedt B, Leppimäki P, and Slotte JP (2002) Cholesterol interactions with phospholipids in membranes. Prog Lipid Res 41:66-97.

Parks JS and Gebre AK (1997) Long-chain polyunsaturated fatty acids in the sn-2 position of phosphatidylcholine decrease the stability of recombinant high density lipoprotein apolipoprotein A-I and the activation energy of the lecithin:cholesterol acyltransferase reaction. J Lipid Res 38:266-275.

Patel H, Ding B, Ernst K, Shen L, Yuan W, Tang J, Drake LR, Kang J, Li Y, Chen Z, et al. (2019) Characterization of apolipoprotein A-I peptide phospholipid interaction and its effect on HDL nanodisc assembly. Int $J$ Nanomedicine 14 3069-3086.

Ramstedt B and Slotte JP (1999) Interaction of cholesterol with sphingomyelins and acyl-chain-matched phosphatidylcholines: a comparative study of the effect of the chain length. Biophys $J$ 76:908-915.

Reißer S, Strandberg E, Steinbrecher T, and Ulrich AS (2014) 3D hydrophobic moment vectors as a tool to characterize the surface polarity of amphiphilic peptides. Biophys J 106:2385-2394.

Remaley AT, Stonik JA, Demosky SJ, Neufeld EB, Bocharov AV, Vishnyakova TG, Eggerman TL, Patterson AP, Duverger NJ, Santamarina-Fojo S, et al. (2001) Apolipoprotein specificity for lipid efflux by the human ABCAI transporter. Biochem Biophys Res Commun 280:818-823.

Remaley AT, Thomas F, Stonik JA, Demosky SJ, Bark SE, Neufeld EB, Bocharov AV, Vishnyakova TG, Patterson AP, Eggerman TL, et al. (2003) Synthetic amphipathic helical peptides promote lipid efflux from cells by an ABCA1-dependent and an ABCA1-independent pathway. J Lipid Res 44:828-836.

Schwendeman A, Sviridov DO, Yuan W, Guo Y, Morin EE, Yuan Y, Stonik J, Freeman L, Ossoli A, Thacker S, et al. (2015) The effect of phospholipid composition of reconstituted HDL on its cholesterol efflux and anti-inflammatory properties. J Lipid Res 56:1727-1737.

Sethi AA, Stonik JA, Thomas F, Demosky S.J, Amar M, Neufeld E, Brewer HB, Davidson WS, D'Souza W, Sviridov D, et al. (2008) Asymmetry in the lipid affinity of bihelical amphipathic peptides. A structural determinant for the specificity of ABCA1-dependent cholesterol efflux by peptides. J Biol Chem 283:32273-32282.

Small D (1986) Handbook of Lipid Research: The Physical Chemistry of Lipids, Plenum Press, New York.

Sorci-Thomas M, Kearns MW, and Lee JP (1993) Apolipoprotein A-I domains involved in lecithin-cholesterol acyltransferase activation. Structure:function relationships. J Biol Chem 268:21403-21409.

Soutar AK, Garner CW, Baker HN, Sparrow JT, Jackson RL, Gotto AM, and Smith LC (1975) Effect of the human plasma apolipoproteins and phosphatidylcholine acyl donor on the activity of lecithin: cholesterol acyltransferase. Biochemistry 14: 3057-3064

Sparks DL, Frank PG, and Neville TA (1998) Effect of the surface lipid composition of reconstituted LPA-I on apolipoprotein A-I structure and lecithin: cholesterol acyltransferase activity. Biochim Biophys Acta 1390:160-172.

Sreerama N and Woody RW (2000) Estimation of protein secondary structure from circular dichroism spectra: comparison of CONTIN, SELCON, and CDSSTR methods with an expanded reference set. Anal Biochem 287:252-260.

Subbaiah PV, Liu M, Bolan PJ, and Paltauf F (1992) Altered positional specificity of human plasma lecithin-cholesterol acyltransferase in the presence of sn-2 arachidonoyl phosphatidyl cholines. Mechanism of formation of saturated cholesteryl esters. Biochim Biophys Acta 1128:83-92.

Tang J, Li D, Drake L, Yuan W, Deschaine S, Morin EE, Ackermann R, Olsen K, Smith DE, and Schwendeman A (2017) Influence of route of administration and lipidation of apolipoprotein A-I peptide on pharmacokinetics and cholesterol mobilization. J Lipid Res 58:124-136.

Tardif J-C, Grégoire J, L’Allier PL, Ibrahim R, Lespérance J, Heinonen TM, Kouz S, Berry C, Basser R, Lavoie M-A, et al.; Effect of rHDL on Atherosclerosis-Safety and Efficacy (ERASE) Investigators (2007) Effects of reconstituted high-density lipoprotein infusions on coronary atherosclerosis: a randomized controlled trial. JAMA 297:1675-1682.

Tardy C, Goffinet M, Boubekeur N, Ackermann R, Sy G, Bluteau A, Cholez G, Keyserling C, Lalwani N, Paolini JF, et al. (2014) CER-001, a HDL-mimetic, 
stimulates the reverse lipid transport and atherosclerosis regression in high cholesterol diet-fed LDL-receptor deficient mice. Atherosclerosis 232:110-118.

Tricoci P, D'Andrea DM, Gurbel PA, Yao Z, Cuchel M, Winston B, Schott R, Weiss R, Blazing MA, Cannon L, et al. (2015) Infusion of reconstituted high-density lipoprotein, CSL112, in patients with atherosclerosis: safety and pharmacokinetic results from a phase 2a randomized clinical trial. J Am Heart Assoc 4:e002171.

Turner S, Voogt J, Davidson M, Glass A, Killion S, Decaris J, Mohammed H, Minehira K, Boban D, Murphy E, et al. (2012) Measurement of reverse cholesterol transport pathways in humans: in vivo rates of free cholesterol efflux, esterification, and excretion. J Am Heart Assoc 1:e001826.

Vecoli C, Cao J, Neglia D, Inoue K, Sodhi K, Vanella L, Gabrielson KK, Bedja D, Paolocci N, L'abbate A, et al. (2011) Apolipoprotein A-I mimetic peptide L-4F prevents myocardial and coronary dysfunction in diabetic mice. J Cell Biochem 112:2616-2626

Wang N, Lan D, Chen W, Matsuura F, and Tall AR (2004) ATP-binding cassette transporters G1 and G4 mediate cellular cholesterol efflux to high-density lipoproteins. Proc Natl Acad Sci USA 101:9774-9779.
Wool GD, Reardon CA, and Getz GS (2008) Apolipoprotein A-I mimetic peptide helix number and helix linker influence potentially anti-atherogenic properties. J Lipid Res 49:1268-1283.

Xu B, Gillard BK, Gotto AM Jr, Rosales C, and Pownall HJ (2017) ABCA1-derived nascent high-density lipoprotein-apolipoprotein AI and lipids metabolically segregate. Arterioscler Thromb Vasc Biol 37:2260-2270.

Clinical Trials gov [Internet]. Bethesda (MD): National Library of Medicine (US). 2000 Feb 29 - . Identifier NCT03473223, Study to investigate CSL112 in subjects with acute coronary syndrome (AEGIS-II); 2018 March 22 [cited 2019 Dec 15]. Available from: https://clinicaltrials.gov/ct2/show/NCT03473223

Address correspondence to: Dr. Anna Schwendeman, Department of Pharmaceutical Sciences, University of Michigan College of Pharmacy, B20102W NCRC, 2800 Plymouth Road, Ann Arbor, MI 48109. E-mail: annaschw@ med.umich.edu 